\title{
Improving the representation of cropland sites in the Community Land Model (CLM) version 5.0
}

\author{
Theresa Boas $^{1,2}$, Heye Bogena ${ }^{1,2}$, Thomas Grünwald ${ }^{3}$, Bernard Heinesch ${ }^{4}$, Dongryeol Ryu ${ }^{5}$, Marius Schmidt ${ }^{1}$, \\ Harry Vereecken ${ }^{1,2}$, Andrew Western ${ }^{5}$, and Harrie-Jan Hendricks Franssen ${ }^{1,2}$ \\ ${ }^{1}$ Institute of Bio- and Geosciences, Agrosphere (IBG-3), Research Centre Jülich, 52425 Jülich, Germany \\ ${ }^{2}$ Centre for High-Performance Scientific Computing in Terrestrial Systems, HPSC TerrSys, \\ Geoverbund ABC/J, 52425 Jülich, Germany \\ ${ }^{3}$ Institute of Hydrology and Meteorology, Technische Universität Dresden (TU Dresden), 01062 Dresden, Germany \\ ${ }^{4}$ Gembloux Agro-Bio Tech (GxABT), University of Liège, 5030 Gembloux, Belgium \\ ${ }^{5}$ Department of Infrastructure Engineering, University of Melbourne, Parkville, VIC 3010, Australia
}

Correspondence: Theresa Boas (t.boas@fz-juelich.de)

Received: 18 July 2020 - Discussion started: 11 August 2020

Revised: 28 November 2020 - Accepted: 8 December 2020 - Published: 28 January 2021

\begin{abstract}
The incorporation of a comprehensive crop module in land surface models offers the possibility to study the effect of agricultural land use and land management changes on the terrestrial water, energy, and biogeochemical cycles. It may help to improve the simulation of biogeophysical and biogeochemical processes on regional and global scales in the framework of climate and land use change. In this study, the performance of the crop module of the Community Land Model version 5 (CLM5) was evaluated at point scale with site-specific field data focusing on the simulation of seasonal and inter-annual variations in crop growth, planting and harvesting cycles, and crop yields, as well as water, energy, and carbon fluxes. In order to better represent agricultural sites, the model was modified by (1) implementing the winter wheat subroutines following $\mathrm{Lu}$ et al. (2017) in CLM5; (2) implementing plant-specific parameters for sugar beet, potatoes, and winter wheat, thereby adding the two crop functional types (CFTs) for sugar beet and potatoes to the list of actively managed crops in CLM5; and (3) introducing a cover-cropping subroutine that allows multiple crop types on the same column within 1 year. The latter modification allows the simulation of cropping during winter months before usual cash crop planting begins in spring, which is an agricultural management technique with a long history that is regaining popularity as it reduces erosion and improves soil health and carbon storage and is commonly used in the regions evaluated in this study. We compared simulation re-
\end{abstract}

sults with field data and found that both the new crop-specific parameterization and the winter wheat subroutines led to a significant simulation improvement in terms of energy fluxes (root-mean-square error, RMSE, reduction for latent and sensible heat by up to $57 \%$ and $59 \%$, respectively), leaf area index (LAI), net ecosystem exchange, and crop yield (up to $87 \%$ improvement in winter wheat yield prediction) compared with default model results. The cover-cropping subroutine yielded a substantial improvement in representation of field conditions after harvest of the main cash crop (winter season) in terms of LAI magnitudes, seasonal cycle of LAI, and latent heat flux (reduction of wintertime RMSE for latent heat flux by $42 \%$ ). Our modifications significantly improved model simulations and should therefore be applied in future studies with CLM5 to improve regional yield predictions and to better understand large-scale impacts of agricultural management on carbon, water, and energy fluxes.

\section{Introduction}

Global climate change is widely believed to have an important impact on future agriculture, and consequently food security under the changing climate is an important research topic (Lobell et al., 2011; Aaheim et al., 2012; Ma et al., 2012; Gosling, 2013; Rosenzweig et al., 2014). With a trend of declining crop yield and increasing uncertainty in yields in 
many parts of the world (Urban et al., 2012; Challinor et al., 2014; Deryng et al., 2014; Rosenzweig et al., 2014; Tai et al., 2014; Levis et al., 2018), understanding the impact of climate change on crop production and improving its prediction at local to global scales is a research topic of great importance to society. In addition, agricultural expansion and management practices exert strong influences on physical and biogeochemical properties of terrestrial ecosystems that need to be considered in model simulations of the terrestrial system. Thus, the evaluation and improvement of integrated modeling approaches, including through incorporation of improved crop phenology, to simulate realistic land management and crop yield in response to climate conditions are the focus of many studies (Stehfest et al., 2007; Olesen et al., 2011; Van den Hoof et al., 2011; Rosenzweig et al., 2014).

Nevertheless, the sophisticated representation of agricultural land cover in Earth system models (ESMs) remains an ongoing challenge due to the complexity of agricultural management decisions and the variety of different crop types and their respective phenologies. In many land surface models (LSMs) and land components of ESMs, the representation of crops is limited to simplistic schemes lacking the representation of management (e.g., irrigation and fertilization) or to surrogate representation by natural grassland (Betts, 2005; Elliott et al., 2015; McDermid et al., 2017). In recent studies there is a trend towards the incorporation of a comprehensive crop module in LSMs. These modules offer improved potential to study changes in water and energy cycles and crop production in response to climate, environment, land use, and land management changes. This may help to improve the simulation of biogeophysical and biogeochemical processes on regional and global scales (Kucharik and Brye, 2003; Lobell et al., 2011; Lokupitiya et al., 2009; Levis et al., 2012; Osborne et al., 2015; McDermid et al., 2017; Lawrence et al., 2018; Lombardozzi et al., 2020). For example, the Simple Biosphere model $(\mathrm{SiB})$ incorporated a crop module to represent a number of temperate crop varieties, which resulted in improved simulated leaf area index (LAI) and net ecosystem exchange (NEE) (Lokupitiya et al., 2009). In addition, the Joint UK Land Environment Simulator (JULES) was extended to a global representation of crops, which improved simulated LAI and gross primary production (GPP) (Osborne et al., 2015).

Recent versions of the Community Land Model (CLM, i.e., 4.0, 4.5, and 5.0) have adopted the prognostic crop module from the Agro-Ecosystem Integrated Biosphere Simulator (Agro-IBIS) (Kucharik and Brye, 2003), which has the ability to simulate the soil-vegetation-atmosphere system including crop yields and has been evaluated in multiple studies (e.g., Twine and Kucharik, 2009; Webler et al., 2012; $\mathrm{Xu}$ et al., 2016). Even the simplified version of the AgroIBIS crop scheme that was implemented in CLM4 led to improved simulation of climate-crop interactions and more comprehensive ecosystem balances than previous CLM versions (Levis et al., 2012). Evaluation studies of CLM4 by
Levis et al. (2012) and Chen et al. (2015) revealed significant sensitivities of energy and carbon fluxes to biases in crop phenology, especially for the seasonality of the NEE for managed crop sites where the flux is governed by planting and harvest times. In its latest version, CLM (CLM5) has been extended with an interactive crop module that represents crop management. It includes eight actively managed crop types (temperate soybean, tropical soybean, temperate corn, tropical corn, spring wheat, cotton, rice, and sugarcane), as well as irrigated and non-irrigated unmanaged crops (Lombardozzi et al., 2020). CLM5 is the only land surface model to date that includes time-varying spatial distributions of major crop types and their management (Lombardozzi et al., 2020). Despite these improvements over earlier versions of CLM, the few studies that evaluated CLM5 at point and regional scales suggest inaccurate phenology and crop yield estimates for specific crops (Chen et al., 2018; Sheng et al., 2018). In summary, current crop modules in LSMs are limited by their ability to represent many different crop types and important management practices such as cover cropping and flexible fertilizer application types and amounts. The main challenges are related to the complex parameterization of simulated crop varieties due to their distinct phenology in combination with information scarcity, as well as the complexity of human interaction through management decisions and biogeochemical processes. In addition to irrigation and fertilizer application, crop rotations and cover cropping are important management practices, and their consideration is a crucial factor to accurately represent energy fluxes and crop phenology of agricultural sites (or areas) over longer timescales.

In western Europe, a large proportion of arable land is cultivated with rotations of different non-perennial cash crops (Kollas et al., 2015; Eurostat, 2018). The most important cash crops grown in the European Union (EU) are cereals, such as wheat (mostly winter wheat varieties in Western Europe), barley, and maize; root crops, such as sugar beet and potatoes; and oilseed crops, such as rapeseed, turnip rapeseed, and sunflowers (Eurostat, 2018). Cereals account for the majority of all crop production in the EU, contributing up to $12 \%$ to global cereal grain production (Eurostat, 2018). The EU production of sugar beet accounts for about half of the global production (Eurostat, 2018). The use of cover crops is a common agricultural management practice to reduce soil erosion, soil compaction, and nitrogen leaching and to increase agricultural productivity by nitrogen fixation (Sainju et al., 2003; Lobell4 et al., 2006; Basche et al., 2014; Plaza-Bonilla et al., 2015; Tiemann et al., 2015; Kaye and Quemada, 2017). The biogeochemical effects and benefits of cover crops, as well as their potential to mitigate climate change, are the focus of many studies (e.g., Sainju et al., 2003; Lobell et al., 2006; Groff, 2015; Plaza-Bonilla et al., 2015; Basche et al., 2016; Carrer et al., 2018; Lombardozzi et al., 2018; Hunter et al., 2019). Despite recent development efforts, the representation of these management practices has not yet been included in CLM5. Furthermore, in a previous 
study by Lu et al. (2017) the default representation of winter cereals performed poorly in simulating the phenology of winter wheat.

In this study, we evaluate and enhance the performance of the crop module of CLM5 focusing on the representation of seasonal and inter-annual variations in crop growth, planting and harvesting cycles, crop yields, and energy and carbon fluxes. Firstly, we transferred the modified vernalization and cold-tolerance routine by Lu et al. (2017) to the CLM5 code to simulate winter cereal in a more meaningful way. Secondly, new crop-specific parameter sets for winter wheat, sugar beet, and potatoes that were gathered from the literature and from observation data were added to the default parameter scheme. Finally, we extended CLM5 by adding a new crop rotation and cover-cropping subroutine that models the growth of winter cover crops and the rotation from a summer to a winter crop within the same year. All modifications were tested at the point scale at four cropland reference sites of the ICOS (Integrated Carbon Observation System) and TERENO (Terrestrial Environmental Observatory) networks in central Europe.

\section{Materials and methods}

\subsection{Community Land Model}

Land surface models such as CLM5 are broadly applied in scientific studies to simulate water, energy, and nutrient fluxes in the terrestrial ecosystem (Niu et al., 2011; Han et al., 2014; Lawrence et al., 2018; Naz et al., 2019). CLM5 represents the latest version of the land component in the Community Earth System Model (CESM) (Lawrence et al., 2018, 2019). In CLM5, simulated land surface fluxes such as latent and sensible heat are driven by atmospheric and meteorological input variables in combination with soil and vegetation states (e.g., soil moisture and LAI) and parameters (e.g., hydraulic conductivity, land cover) (Oleson et al., 2010; Lawrence et al., 2011; Lawrence et al., 2018). The new biogeochemistry and crop module of CLM5 (BGC-Crop) adopted the prognostic crop module from the Agro-Ecosystem Integrated Biosphere Simulator (Agro-IBIS) (Kucharik and Brye, 2003). This incorporation of agriculturally managed land cover may help to improve the general representation of biogeochemical processes on the global scale to better address challenges from land use changes and agriculture practices (e.g., Lobell et al., 2006). The CLM5 crop module includes new crop functional types, updated fertilization rates and irrigation triggers, a transient crop management option, and some adjustments to phenological parameters. In addition, extensive modifications have been made to the grain $\mathrm{C}$ and $\mathrm{N}$ pool. For example, $\mathrm{C}$ for annual crop seeding comes from the grain $\mathrm{C}$ pool, and initial seed $\mathrm{C}$ for planting is increased from 1 to $3 \mathrm{gC} \mathrm{m}^{-2}$ (Lawrence et al., 2018, 2019; Lombardozzi et al., 2020).
Vegetated land units are separated into natural vegetation and crop land units, with only one crop functional type (CFT) on each soil column, including irrigation as a CFT-specific land management technique (Lawrence et al., 2018; Lombardozzi et al., 2020). A total of 78 plant and crop functional types are included in CLM5, including an irrigated and unirrigated unmanaged $\mathrm{C}_{3}$ crop; 8 actively managed crop types - spring wheat, temperate and tropical corn, temperate and tropical soybean, cotton, rice, and sugarcane; and 23 crop types without specific crop parameters associated with them that are merged to the most closely related and parameterized CFTs (Lombardozzi et al., 2020). For the simulation of those inactive crop types, the specific crop parameters of the spatially closest and most similar out of the eight active crop types are used. Irrigation is simulated dynamically for defined irrigated CFTs in response to soil moisture conditions and is partly based on the implementation of Ozdogan et al. (2010) (Leng et al., 2013; Lawrence et al., 2018).

Besides water availability from irrigation and precipitation, crop yield and food productivity greatly depends on fertilization. In CLM5-BGC-Crop, fertilization is represented by adding nitrogen directly to the soil mineral pool (Lawrence et al., 2018). Fertilization dynamics and annual fertilizer amounts depend on the crop functional types and vary spatially and yearly based on the land use and land cover change time series derived from the Land Use Model Intercomparison Project (Lawrence et al., 2019). In CLM5, land fractions with natural vegetation are not influenced by fertilizer application. In cropping units, mineral fertilizer application starts during the leaf-emergence phase of crop growth and continues for $20 \mathrm{~d}$. Manure nitrogen is applied at slower rates $\left(0.002 \mathrm{~kg} \mathrm{~N} \mathrm{~m}^{-2} \mathrm{yr}^{-1}\right.$ by default) to prevent rapid denitrification rates that were observed in earlier CLM versions so that more uptake by the plant is achieved (Lawrence et al., 2018).

CLM5-BGC-Crop is fully prognostic with regards to carbon and nitrogen in the soil, vegetation, and litter at each time step. The crop phenology and the carbon and nitrogen cycling processes follow three phenology phases: phase (1) from planting to leaf emergence, phase (2) from leaf emergence to beginning of grain fill, and phase (3) from beginning of grain fill to maturity and harvest. These phenology phases are governed by temperature thresholds and the percentage of growing degree days (GDDs) required for maturity of the crop, with harvest occurring when maturity is reached (Lombardozzi et al., 2020).

The first phenology stage, planting, starts when crop specific $10 \mathrm{~d}$ mean temperature thresholds (of both the daily $2 \mathrm{~m}$ air temperature $T_{10 \mathrm{~d}}$ and the daily minimum $2 \mathrm{~m}$ air temperature $\left.T_{\min , 10 \mathrm{~d}}\right)$ are met. The transition from planting to leaf emergence (phase 2) begins when the growing degree days of soil temperature at $0.05 \mathrm{~m}$ depth $\left(\mathrm{GDD}_{\mathrm{Tsoi}}\right)$ reaches $1 \%-5 \%$ of the GDDs required for maturity $\left(\mathrm{GDD}_{\mathrm{mat}}\right)$, depending on a crop-specific base temperature for the GDD $\mathrm{Tsoi}_{\text {. }}$ Grain fill (phase 3) starts with either the simulated $2 \mathrm{~m}$ air 
temperature $\left(\mathrm{GDD}_{\mathrm{T} 2 \mathrm{~m}}\right)$ reaching a heat unit threshold $(\mathrm{h})$ of $40 \%-65 \%$ of GDD mat or when the maximum leaf area in$\operatorname{dex}\left(L_{\max }\right)$ is reached. The crop is harvested in one time step when $100 \% \mathrm{GDD}_{\text {mat }}$ is reached or when the crop-specific maximum number of days past planting is exceeded. The LAI is dependent on the specified specific leaf area (SLA) and the calculated leaf C. The SLA and the maximum LAI are specified for each crop in the parameter file (Table A2).

The allocation of carbon and nitrogen also follows the phenology phases. During the leaf-emergence phase, carbon from the seed carbon pool is transferred to the leaf carbon pool. Nitrogen is supplied through the soil mineral nitrogen pool. During the grain-fill phases, nitrogen from the leaf and stem of the plant is translocated to the grain pool. Allocation ends upon harvest of the crop, when grain carbon and nitrogen are transferred from the grain pool to the grain product pool and a small amount $\left(3 \mathrm{gC} \mathrm{m}^{-2}\right)$ is transferred to the seed carbon pool for the next planting (Lawrence et al., 2018; Lombardozzi et al., 2020).

The total amount of assimilated carbon and nitrogen is regulated by availability of soil nitrogen, among other resources, and also depends on crop-specific target $\mathrm{C} / \mathrm{N}$ ratios in the plant tissue (varying for roots, stem, leaves, reproductive pools) (Lawrence et al., 2018; Lombardozzi et al., 2020). For a detailed technical description of the model and all its features, the reader is referred to the technical documentation and description of new features in CLM5 (Lawrence et al., 2018, 2019; Lombardozzi et al., 2020).

\subsection{Model modifications}

In the course of this study, three main limitations of CLM5 for the intended simulation of agricultural sites in western Europe at point scale were identified: (1) the default CLM5BGC-Crop code and parameterization yielded a very poor representation of crop growth of winter wheat and other winter crops, (2) the default plant parameter data set lacks specific parameterization for several important cash crops (here sugar beet and potatoes in particular), and (3) CLM5-BGCCrop does not allow a second crop growth onset or a second CFT to be grown on the same field within 1 year. These limitations were resolved by modifications to the code structure and parameterization of the CLM5-BGC-Crop module described below.

\subsubsection{Winter cereal representation}

Winter wheat is an important crop for global food production and covers a significant fraction of the European croplands (Chakraborty and Newton, 2011; Vermeulen et al., 2012). In general, winter wheat is exposed to a different range of environmental stresses compared to summer crops, such as low temperatures. In regions with sufficiently cold winters, the main processes that allow a successful cultivation of winter wheat during the colder months are vernalization and cold tolerance (Barlow et al., 2015; Chouard, 1960). Vernalization represents the process that an exposure to a period of nonlethal low temperatures is required to enter the flowering stage for winter crops. In general, the vernalization process ensures that the reproductive development of plants growing over winter (winter crops and also natural vegetation) does not start in late summer or fall but rather in late winter or spring. The other process, cold tolerance, ensures that the crop can acclimate to low temperatures and thus survive cold temperatures and even freeze-thaw cycles. However, cold damage to the crop can occur when the crop is exposed to low temperatures at a certain development stage. These damages have been documented to have significant impacts in crop yield (Lu et al., 2017). Lu et al. (2017) introduced a new vernalization, as well as a cold-tolerance and frost damage subroutine in CLM4.5 to better simulate the phenology of winter cereal. For this, they adapted the winter wheat vernalization model from Streck et al. (2003). Streck et al. (2003) evaluated their vernalization algorithm for a wide range of winter wheat cultivars for the purpose of being used in crop model approaches. Furthermore, Lu et al. (2017) implemented a cold-tolerance scheme that includes frost damage representation using the approaches of Bergjord et al. (2008) and Vico et al. (2014). In this study, their modifications were ported to the newer version of the model, CLM5, and tested for several study sites.

Vernalization and cold tolerance are cumulative processes that operate in certain optimum temperature ranges (which can be different for different crop types and cultivars). The vernalization process starts after leaf emergence and ends before flowering (Streck et al., 2003) and is dependent on the crown temperature $\left(T_{\text {crown }}\right)$ (see Eq. A1). The crown is the connecting tissue between the roots and the shoots at the base of the plant. For winter wheat, the crown node is located at about 3-5 cm soil depth (Aase and Siddoway, 1979). The daily vernalization dependence is calculated based on $T_{\text {crown }}$, and the optimum vernalization temperature $\left(T_{\mathrm{opt}}\right)$ is limited to times when the crown temperature lies within the minimum to maximum vernalization temperature $\left(T_{\min }\right.$ and $T_{\max }$ ) range:

$$
\begin{aligned}
& \mathrm{vd}=\sum \mathrm{fvn}\left(T_{\text {crown }}\right), \\
& \mathrm{fvn}\left(T_{\text {crown }}\right)= \\
& \frac{2\left(T_{\text {crown }}-T_{\min }\right)^{\alpha}\left(T_{\mathrm{opt}}-T_{\min }\right)^{\alpha}-\left(T_{\text {crown }}-T_{\min }\right)^{2 \alpha}}{\left(T_{\mathrm{opt}}-T_{\min }\right)^{2 \alpha}}, \\
& \alpha=\frac{\ln 2}{\ln \left[\left(T_{\max }-T_{\min }\right) /\left(T_{\mathrm{opt}}-T_{\min }\right)\right],} \\
& \mathrm{vf}=\frac{\mathrm{vd}^{5}}{22.5^{5}+\mathrm{vd}^{5},}
\end{aligned}
$$

where vd (-) is the sum of the sequential vernalization days; fvn (-) is the daily vernalization rate; vf $(-)$ is the vernalization factor; $T_{\text {crown }}(\mathrm{K})$ is the crown temperature; and $T_{\mathrm{opt}}$ 
(K), $T_{\max }(\mathrm{K})$, and $T_{\min }(\mathrm{K})$ are the optimum, maximum, and minimum vernalization temperatures, respectively.

The vernalization factor can range between 0 (not vernalized) and 1 (fully vernalized). It is multiplied with the GDD value during the phenology phase after planting and the grain carbon allocation coefficient, which leads to a reduced growth rate in the beginning of the phenology cycle until the plant is fully vernalized. The vernalization factor is further used in the cold-tolerance subroutine to assess the cumulative cold hardening of the plant and the dehardening process when exposed to higher temperatures (see below). Lu et al. (2017) introduced a scheme to quantify the impacts of frost damage based on the approaches following Bergjord et al. (2008) and Vico et al. (2014). The damage from low temperatures is quantified by three main variables: the temperature at which $50 \%$ of the plant is damaged $\left(\mathrm{LT}_{50}\right)$, the survival probability $\left(f_{\text {surv }}\right)$, and winter killing degree days (WDDs) (Bergjord et al., 2008; Lu et al., 2017; Vico et al., 2014). A detailed description of these approaches can be found in Bergjord et al. (2008) and Vico et al. (2014).

The temperature at which $50 \%$ of the plant is damaged $\left(\mathrm{LT}_{50}\right)$ is calculated interactively at each time step $\left(\mathrm{LT}_{50, t}\right)$ depending on the previous time step $\left(\mathrm{LT}_{50, t-1}\right)$ and on several accumulative parameters. These parameters are the exposure to near-lethal temperatures $\left(\right.$ rate $\left._{\mathrm{s}}\right)$, the stress due to respiration under snow $\left(\right.$ rate $\left._{\mathrm{r}}\right)$, the cold hardening or lowtemperature acclimation (contribution of hardening, rate $_{h}$ ), and the loss of hardening due to the exposure to a period of higher temperatures (dehardening, rate $_{d}$ ) that are each functions of the crown temperature (Lu et al., 2017, and references therein) (see Eqs. A2-A11).

The survival rate $\left(f_{\text {surv }}\right)$ is then calculated as a function of $\mathrm{LT}_{50}$ and the crown temperature. The probability of survival is a function of $T_{\text {crown }}$ in time $(t)$. It increases once $T_{\text {crown }}$ is higher than $\mathrm{LT}_{50}$ and decreases when it is lower than $\mathrm{LT}_{50}$ (Vico et al., 2014):

$f_{\text {surv }}\left(T_{\text {crown }}, t\right)=2^{-\frac{T_{\text {crown }} \alpha_{\text {surv }}}{L T_{50}}}$,

where $\alpha_{\text {surv }}$ is a shape parameter of 4 .

The winter killing degree day (WDD) is calculated as a function of crown temperature and survival probability, where the maximum function limits the integration to the potentially damaging periods and when the air temperature $(T)$ is lower than the base temperature $\left(T_{\text {base }}\right)$ of $0^{\circ} \mathrm{C}$ (Vico et al., 2014):

$$
\begin{gathered}
\mathrm{WDD}=\int_{\text {winter }} \max \left[\left(T_{\text {base }}-T_{\text {crown }}\right), 0\right] \\
{\left[1-f_{\text {surv }}\left(T_{\text {crown }}, t\right)\right] \mathrm{d} t .}
\end{gathered}
$$

Lower $\mathrm{LT}_{50}$ indicates a higher frost tolerance and would result in higher survival rates, smaller WDD, and less cold damage to the plant. Thus, when the survival probability and crown temperature are low, the WDD will be high (Vico et al., 2014).

Lu et al. (2017) also implemented a relationship between frost damage described above and the subsequent growth or carbon allocation of the plant. Whenever the survival factor is less than 1 , a small amount of leaf carbon $\left(5 \mathrm{gC} \mathrm{m}^{-2}\right.$ per model time step) and a small amount of leaf nitrogen (scaled by the prescribed $\mathrm{C} / \mathrm{N}$ target ratios; see Table 1 and Table A2) are transferred to the soil carbon and nitrogen litter pool, thus simulating a reduction in growth and/or damage of small and young leaves and seedlings. Additionally, in order to simulate more drastic and instantaneous damage or death of the plant due to a longer duration of lethal temperatures (most likely to occur in spring when the plant has emerged and is close to or already fully vernalized), a second frost damage function is implemented. When WDD $>1^{\circ} \mathrm{d}$, the frost damage function is triggered, leading to crop damage by transferring leaf carbon (amount scaled by the survival probability $\left.\left(1-f_{\text {surv }}\right)\right)$ to the soil carbon litter pool.

A more detailed description of these routines can be found in the source literature ( $\mathrm{Lu}$ et al., 2017, and references therein).

\subsubsection{Crop-specific parameterization}

In order to yield a reasonable representation of agricultural areas on the regional scale in future studies, the default parameter set was extended with specific crop parameters for sugar beet, potatoes, and winter wheat based on the characteristics of our study sites to better fit the observed plant phenology and energy fluxes at the simulation sites.

The CFTs sugar beet and potatoes are merged to the spring wheat CFT on the default parameter scheme due to the lack of crop-specific parameters for these crops. For winter wheat there is a preexisting default parameter set available in CLM5. However, this default parameterization performed poorly in representing the crop phenology for the evaluated study sites in this study. This was also reported in an earlier study by Lu et al. (2017). Thus, crop-specific parameters were added for sugar beet, potatoes, and winter wheat. The parameters to be modified were selected taking into account the sensitivity analysis and parameter estimation studies by Post et al. (2017) (for version 4.5), Cheng et al. (2020), and Fisher et al. (2019) (for version 5.0). Key parameters as identified by previous studies (Sulis et al., 2015; Post et al., 2017; Lu et al., 2017; Fisher et al., 2019; Cheng et al., 2020) are listed in Table 1. These parameters were added with values from the literature or site-specific observations to match observed values. General phenology parameters such as the maximum canopy height, planting temperatures, maximum LAI, maximum and minimum planting dates, and days for growing were adjusted according to field data, including planting and harvest dates. A list of plant types and planting and harvest dates is provided in Table A1. $\mathrm{C} / \mathrm{N}$ ratios in leaves and roots for wheat and sugar beet were adapted from 
Table 1. CFT-specific phenology, carbon and nitrogen ratios, and allocation parameters.

\begin{tabular}{|c|c|c|}
\hline Parameter & CLM variable name & Units \\
\hline \multicolumn{3}{|l|}{ Phenology } \\
\hline Minimum planting date for the Northern Hemisphere & min_NH_planting_date & MM.DD \\
\hline Maximum planting date for the Northern Hemisphere & max_NH_planting_date & MM.DD \\
\hline Average 5 day daily temperature needed for planting & planting_temp & $\mathrm{K}$ \\
\hline Average $5 \mathrm{~d}$ daily minimum temperature needed for planting & min_planting_temp & $\mathrm{K}$ \\
\hline Minimum growing degree days & gddmin & ${ }^{\circ} \mathrm{d}$ \\
\hline Maximum number of days to maturity & mxmat & Days \\
\hline Growing degree days for maturity & hygdd & ${ }^{\circ} \mathrm{d}$ \\
\hline Base temperature for GDD & baset & ${ }^{\circ} \mathrm{C}$ \\
\hline Maximum temperature for GDD & mxtmp & ${ }^{\circ} \mathrm{C}$ \\
\hline Percentage of GDD for maturity to enter phase 3 & lfemerg & $\%$ GDDmat \\
\hline Percentage of GDD for maturity to enter phase 4 & grnfill & $\%$ GDDmat \\
\hline Canopy top coefficient & ztopmax & M \\
\hline Maximum leaf area index & laimx & $\mathrm{m}^{2} \mathrm{~m}^{-2}$ \\
\hline Specific leaf area & slatop & $\mathrm{m}^{2} \mathrm{gC}^{-1}$ \\
\hline \multicolumn{3}{|l|}{$\mathrm{CN}$ ratios and allocation } \\
\hline Leaf $\mathrm{C} / \mathrm{N}$ & leafcn & $\mathrm{gC} \mathrm{gN}^{-1}$ \\
\hline Minimum leaf $\mathrm{C} / \mathrm{N}$ & leafcn_min & $\mathrm{gC}_{\mathrm{gN}^{-1}}$ \\
\hline Maximum leaf $\mathrm{C} / \mathrm{N}$ & leafcn_max & $\mathrm{gC} \mathrm{gN}^{-1}$ \\
\hline Fine $\operatorname{root} \mathrm{C} / \mathrm{N}$ & frooten & $\mathrm{gC} \mathrm{gN}^{-1}$ \\
\hline Grain $\mathrm{C} / \mathrm{N}$ & graincn & $\mathrm{gC} \mathrm{gN}^{-1}$ \\
\hline Fraction of leaf $\mathrm{N}$ in RuBisCo & flnr & fraction per $\mathrm{gNm}^{-2}$ \\
\hline
\end{tabular}

Whitmore and Groot (1997), Gan et al. (2011), SánchezSastre et al. (2018), and Zheng et al. (2018). The specific leaf area (slatop) and the fraction of leaf $\mathrm{N}$ in RuBisCo (flnr) for sugar beet and winter wheat were taken from Sulis et al. (2015) and references therein and also adopted for potatoes.

Table A2 provides a full list of default and newly added crop-specific parameters for the CFTs temperate corn, spring wheat, sugar beet, potatoes, and winter wheat.

\subsubsection{Cover-cropping and crop rotation scheme}

The effect of cover crops on the physical and biogeochemical properties of the land surface alters latent heat flux, albedo, and soil carbon and nitrogen storage and can potentially impact local and regional climate (Sainju et al., 2003; Lobell et al., 2006; Möller and Reents, 2009; Plaza-Bonilla et al., 2015; Basche et al., 2016; Carrer et al., 2018; Lombardozzi et al., 2018; Hunter et al., 2019).

In the default BGC phenology, the growth algorithm starts in the beginning of each year, when the crop is not alive on the specific patch. Furthermore, the CLM structure does not allow multiple CFTs to coexist on the same column so that multiple planting phases related to cover cropping over winter months or crop rotations with winter and summer crops, both being very common practices in Europe and worldwide, cannot be accounted for. This might also be an issue when representing ecosystems where agricultural management practices involve multiple sowing and harvest cycles in accordance with the monsoon season (e.g., India). Therefore, a cover-cropping subroutine was implemented in the BGC phenology module that affects the onset-offset (crop cycle/fallow) algorithm to allow a second onset period (crop cycle) on the same column.

A cover crop flag was introduced in the parameter file and in the source code. This flag can be set for any CFT in the parameter file and calls the cover-cropping subroutine when it is set to true (covercrop_flag $\neq 0$ ). This allows a flexible handling of this option and for its application on a larger scale. With this modification, the onset period can start again within 1 simulation year for another (or the same) CFT. For example, when the maturity of the crop is reached and it has been harvested, the model would by default switch to the next stage (phase 4), where the crop is not alive and the offset (fallow) period begins. The next onset period and GDD accumulation for planting would then start in the subsequent simulation year. In our modified CLM5 version, the covercropping subroutine is called before entering into the offset period when the cover-crop flag for the current CFT is set to true. In the cover-cropping subroutine, the CFT is then changed according to a predefined rotation scheme, and another onset period and GDD accumulation for planting is initialized. 
A common practice is to plow the cover crops into the soil instead of removing their biomass from the field. We simulated this by relocating the biomass of the crop into the litter pool instead of the grain product pool upon harvest using the use_grainproduct flag described below (Eq. 7).

Individual crop rotation schemes were customized within the code and depend on the currently planted crop type. For example, if a simulation starts with a crop coverage of spring wheat specified in the surface file, the new subroutine is called after harvest of the crop. Within the subroutine, the CFT is then changed to the next crop, e.g., sugar beet. After the harvest of this crop, e.g., sugar beet, the CFT is again changed to the next crop and so on. When the CFT is changed back to spring wheat, the rotation cycle starts again. This rotation is defined in a repetitive sequence based on the harvested CFT and its harvest date:

if harvdate $(p) \geq \operatorname{hd}_{1}$ and $\operatorname{ivt}(p)=\operatorname{crop}_{1}$ then

$$
\begin{aligned}
& \operatorname{ivt}(p)=\operatorname{crop}_{2} \\
& \operatorname{croplive}(p)=\text { false } \\
& \operatorname{idop}(p)=\text { not_planted } \\
& \text { use_grainproduct }=\text { true }
\end{aligned}
$$

else if harvdate $(p) \geq \operatorname{hd}_{2}$ and $\operatorname{ivt}(p)=\operatorname{crop}_{2}$ then

$$
\begin{aligned}
& \operatorname{ivt}(p)=\operatorname{crop}_{3} \\
& \operatorname{croplive}(p)=\text { false } \\
& \operatorname{idop}(p)=\text { not_planted } \\
& \text { use_grainproduct }=\text { true, }
\end{aligned}
$$

where harvdate is the harvest day of the current simulation year, hd is the customizable harvest date of the respective CFT, $p$ is the simulated patch on the model grid, ivt is the simulated CFT, crop $1-3$ represent the user-specified CFTs to the rotated, idop is the planting day, and use_grainproduct is a flag to define whether the grain carbon of simulated crop is to be harvested into the food pool or not. If this flag is set to false, the plant carbon and nitrogen are transferred to the soil litter pool and not allocated to the food product pool upon harvest of the crop.

The actual rotation of crop types can be customized by the user by defining the variables hd and $\operatorname{crop}_{x}$ in a list (e.g., $\mathrm{hd}_{1}=150$ [day of year], crop $_{1}=$ spring wheat). By including the harvest date as a dependency, it is also possible to simulate the planting of cover crops based on harvest date thresholds. A user-defined maximum harvest date for any specific cash crop can define whether a cover crop would be planted or not. This technique can be beneficial to study the effects of conceptual cover-cropping scenarios on regional scales. The possibility to change the CFT within the same year represents a significant improvement in flexibility, as CLM5 only permitted land use changes at the beginning of every year. In order to simulate cover cropping at our study site DE-RuS, we implemented a new CFT for a greening mix cover crop (or covercrop 1 ).

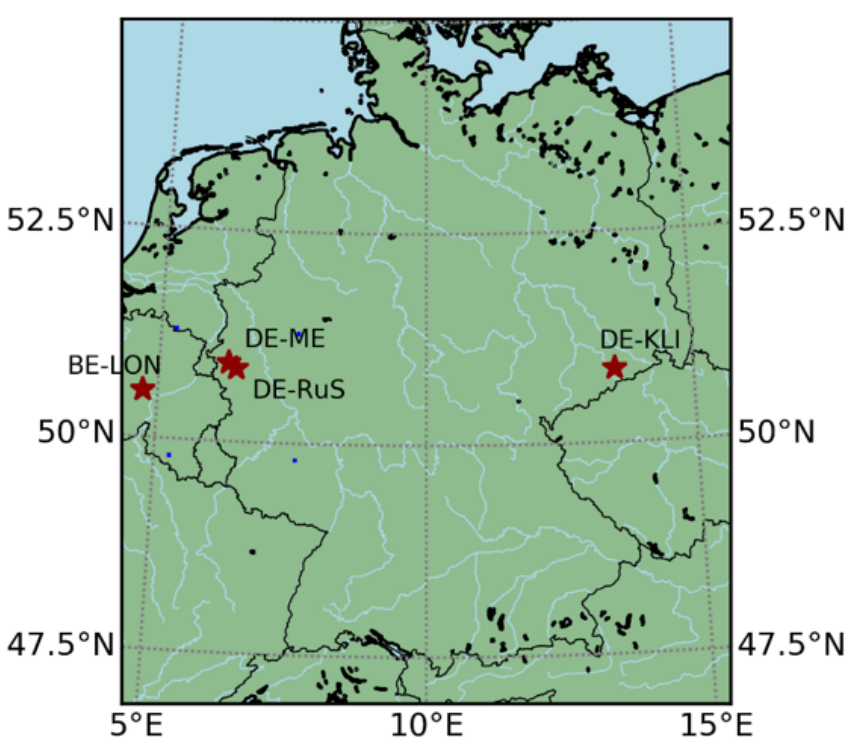

Figure 1. ICOS and TERENO cropland study sites Selhausen (DE-RuS), Merzenhausen (DE-RuM), Klingenberg (DE-Kli), and Lonzée (BE-Lon).

\subsection{Study sites and validation data}

The CLM5 model was set up for four European cropland sites: Selhausen, Merzenhausen, Klingenberg, and Lonzée (Fig. 1). These sites were selected mainly for their excellent continuous measurements of surface energy fluxes.

Selhausen $\left(50.86589^{\circ} \mathrm{N}, 6.44712^{\circ} \mathrm{E}\right)$ is part of the TERENO Rur Hydrological Observatory (Bogena at al., 2018) and the Integrated Carbon Observation System (ICOS, 2020). The test site covers an area of approximately $1 \mathrm{~km} \times 1 \mathrm{~km}$ and is located in the catchment of the Rur river (Bogena et al., 2018). Selhausen had a crop rotation of sugar beet (Beta vulgaris), winter wheat (Triticum aestivum), and winter barley (Hordeum vulgare) and also less frequently featured rapeseed (Brassica napus) and potatoes (Solanum tuberosum) from 2015 to 2019. Cover crops such as oilseed radish or cover crop mixes are planted occasionally between two main crop rotations. Continuous records of meteorological variables, soil-specific observations, and greenhouse gas and energy fluxes have been available for Selhausen since 2011. Regular LAI measurements have been available since 2016 (Ney and Graf, 2018).

Merzenhausen $\left(50.93033^{\circ} \mathrm{N}, 6.29747^{\circ} \mathrm{E}\right)$ is located at approximately $14 \mathrm{~km}$ from Selhausen and is also part of the TERENO Rur Hydrological Observatory. The crop rotation of the site includes sugar beet (Beta vulgaris), winter wheat (Triticum aestivum), winter barley (Hordeum vulgare), rapeseed (Brassica napus), and occasionally catch cover crop mixes. For Merzenhausen, continuous records of meteorological variables, soil-specific observations, and energy fluxes have been available since 2011. Regular LAI measurements were available from 2016 to 2018 . 
Klingenberg $\left(50.89306^{\circ} \mathrm{N}, 13.52238^{\circ} \mathrm{E}\right)$ is an ICOS cropland site located in the mountain foreland of the Erzgebirge that is operated by the Technical University Dresden (TU Dresden) (ICOS, 2020; Prescher et al., 2010). The site is characterized as managed cropland with a 5-year planting rotation of rapeseed (Brassica napus), winter wheat (Triticum aestivum), maize (Zea mays), and spring and winter barley (Hordeum vulgare) (Kutsch et al., 2010). Since 2004, data on ecosystem fluxes (including net ecosystem and net biome productivity), meteorological variables, and soil observations have been collected. Furthermore, biomass observations and agricultural management information are available for this site.

The cropland site Lonzée $\left(50.553^{\circ} \mathrm{N}, 4.746^{\circ} \mathrm{E}\right)$ in Belgium is also part of ICOS (Buysse et al., 2017). It has been planted in a 4-year rotation cycle with sugar beet (Beta vulgaris), winter wheat (Triticum aestivum), and potato (Solanum tuberosum) since 2000, with mustard as a cover crop after winter wheat harvest (Moureaux, 2006; Moureaux et al., 2008). For Lonzée, continuous records of meteorological variables, EC flux data, and LAI (GLAI and GAI) measurements are available from 2004 onwards. General information on the ICOS study sites, such as climatic conditions and soil types, is provided on the ICOS Carbon Portal under the respective site codes (ICOS, 2020).

At all sites, the application of mineral fertilizer and herbicides or pesticides, as well as occasional application of organic fertilizer, is regular management practice.

Station data required to force CLM, i.e., meteorological variables (see the following section), were measured as block averages over $10 \mathrm{~min}$ or at higher resolutions and gap-filled using linear statistical relations to nearby stations where possible (Graf, 2017) or by marginal distribution sampling within the software package REddyProc otherwise (Wutzler et al., 2018). Fluxes required for model validation (i.e., net ecosystem $\mathrm{CO}_{2}$ exchange (NEE), latent heat flux (LE), sensible heat flux $(H)$, soil heat flux $(G)$, and gross primary production (GPP)) and net radiation (Rn) were either measured ( $G$ and $\mathrm{Rn}$ ) or computed from turbulent raw measurements (frequency $\geq 10 \mathrm{~s}^{-1}$ ) using the eddy covariance method for 30 min block averages by the respective site operators. Subsequently, gaps were filled and GPP was estimated from NEE using REddyProc (Wutzler et al., 2018). More details on quality control, filling of longer gaps and by nearby stations, correction of soil heat flux, and energy balance closure analysis are given in Graf et al. (2020), and these data sets are specifically given for DE-RuS and DE-RuM, including LAI measurements, in Reichenau et al. (2020). The long-term annual energy balance closures of the sites DE-RuS, DE-Kli, and BE-Lon were approximately $79 \%, 77 \%$, and $76 \%$, respectively, according to analyses in Graf et al. (2020), and $76 \%$ at DE-RuM according to an earlier study by Eder et al. (2015). All half-hourly meteorological and flux data were aggregated to hourly averages to match our customized CLM forcing time step.
Site-specific measurement records of latent and sensible heat fluxes, net ecosystem exchange (NEE), LAI, soil temperature, and soil moisture were used as validation data for the simulation runs.

Forcing variables were always used in gap-filled form, while validation variables were used in unfilled, qualityfiltered form.

\section{Experimental design and analyses}

\subsection{Model implementation}

For the single-point study sites, CLM was run in point mode with only one grid cell and forced with site-specific hourly meteorological data. The annual fertilization amounts at the single-point study sites were adjusted according to documented amounts of applied fertilizer that ranged between 12 and $20 \mathrm{gN} \mathrm{m}^{-2}$. In CLM5, the potential photosynthetic capacity and the total amount of assimilated carbon during the phenology stages are regulated by the availability of soil nitrogen (Lawrence et al., 2018). With modern fertilization practices in Europe, nitrogen is not assumed to be a limiting factor for the studied sites.

In order to balance ecosystem carbon and nitrogen pools, gross primary production and total water storage in the system, a spin-up is required (Lawrence et al., 2018). An accelerated decomposition spin-up of 600 years and an additional spin-up of 400 years was conducted for each site with the BGC-Crop module (Lawrence et al., 2018; Thornton and Rosenbloom, 2005). The simulated conditions at the end of the spin-up were then used as initial conditions for the following simulations.

In order to test the winter wheat representation, several simulations were conducted for all winter wheat years at the sites DE-RuS, DE-RuM, DE-Kli, and BE-Lon. In a first step, the impact of each modification was assessed individually by simulating one winter wheat year at the site DE-RuS using four different model configurations: (1) the default model and default parameter set (control), (2) the default model with the new parameter set (control + crop-specific), (3) the extended winter wheat model with the default parameter set (new routine), and (4) the extended winter wheat model with the new parameter set (new routine + cropspecific). Further evaluations for the other study sites and years were conducted for the combined winter wheat modifications CLM_WW (extended model with winter wheat subroutines and new crop-specific parameterization) in comparison to control simulations (default model configuration and default parameterization of winter wheat).

For the evaluation of the crop-specific parameter sets for sugar beet and potatoes, simulations were run with the new parameterizations at the sites DE-RuS and BE-Lon over several years. For both sites, control simulations were conducted without the new parameter set, in which both CFTs sugar 
beet and potatoes are simulated as a spring wheat by default. Furthermore, an evaluation of the default parameterization for the CFT temperate corn at the site DE-Kli is included in the Supplement (Fig. S1, Table S1).

The cover-cropping and crop rotation scheme was tested for two practical cases at DE-RuS. From 2016 to 2017, planting was altered at DE-RuS from barley (here represented by the CFT for spring wheat) in 2016 to sugar beet in 2017 with a greening mix cover crop in between (winter months 2016/2017). In order to simulate this common cover-cropping practice, we implemented a new CFT for a greening mix cover crop (or covercrop 1 ). For the years 2017 to 2019 at DE-RuS, the subroutine's ability to simulate realistic crop rotation cycles was tested by changing the simulated CFT from sugar beet (2017) to winter wheat (20172018) and then to potatoes (2019). In this step, simulations were run with the previously tested crop-specific parameterizations for sugar beet, potatoes, and winter wheat. Simulation results were again compared to a control simulation run, where a consecutive growth of spring wheat is simulated.

\subsection{Evaluation of model performance}

For statistical evaluation of the model results, the root-meansquare error (RMSE), the bias (BIAS), and the Pearson correlation $(r)$ were chosen as performance metrics:

$$
\begin{aligned}
& \text { RMSE }=\sqrt{\frac{1}{n} \sum_{i=1}^{n}\left(X_{i}-X_{\mathrm{obs}, i}\right)^{2},} \\
& \mathrm{BIAS}=\sum_{i=1}^{n}\left(X_{i}-X_{\mathrm{obs}, i}\right) / \sum_{i=1}^{n}\left(X_{\mathrm{obs}, i}\right), \\
& r=\left(\frac{1}{n} \sum_{i=1}^{n}\left(X_{\mathrm{obs}, i}-\mu_{\mathrm{obs}}\right) \cdot\left(X_{i}-\mu_{\mathrm{sim}}\right)\right) \\
& \quad /\left(\sigma_{\mathrm{sim}} \cdot \sigma_{\mathrm{obs}}\right),
\end{aligned}
$$

where $i$ is time step and $n$ the total number of time steps. $X_{i}$ and $X_{\mathrm{obs}, i}$ are the simulated and the observed values at every time step, with $\mu_{\text {sim }}$ and $\mu_{\text {obs }}$ being the respective mean values. The standard deviation of simulation results and measurement data are represented by $\sigma_{\text {sim }}$ and $\sigma_{\text {obs }}$, respectively.

The statistical evaluation was conducted for daily simulation output and daily observation data for the variables NEE, LE, $H$, and Rn.

\section{Results}

\subsection{Winter cereal representation}

The impact of the new winter-wheat-specific parameterization and the new winter wheat routine, as well as the combination of both, is illustrated in Fig. 2. Here we show simulated LAI for the default model and default parameter set (control), the default model with the new parameter set (control + crop-specific), the extended winter wheat model with the default parameter set (new routines), and the extended winter wheat model with the new parameter set (new routines + crop specific).

Using only the new crop-specific parameter set with the default model configuration resulted in slightly higher LAI values compared to the control run but did not reach the observed maximum LAI values and the growth cycle duration. The implementation of the winter wheat subroutines using the default parameter set led to a more realistic reproduction of the growth cycle duration compared to the control run but did not yield good correspondence with observed LAI magnitudes. The combination of the new crop-specific parameter set and the new winter wheat subroutines resulted in the most realistic LAI dynamics (Fig. 2). As previously described by Lu et al. (2017), the default vernalization routine reaches a factor of 1 (fully vernalized) shortly after planting when the first frost occurs. This induced an unrealistically early commencement of the grain-fill stage within 2 months after planting in the control run (November or December). The default vernalization also resulted in peak LAI occurring too early in the year, leading to significantly lower photosynthesis compared to the observations. This also applies to the implementation of the new crop-specific parameter set, which generally leads to slightly higher LAI values.

In the extended winter wheat model, the adapted vernalization routine produces lower initial vernalization factors, which reduce the growing degree days. This leads to later onset of the leaf-emergence and grain-fill stage and allows a more realistic representation of the LAI cycle and peak in combination with the new crop-specific parameterization.

In further evaluations, the combined winter wheat package, including the new crop-specific parameterization and the extended winter wheat subroutines, is implemented in CLM_WW simulations and compared to control runs (Fig. 3). For all study sites and simulation years, CLM_WW simulations resulted in a much better representation of the growth cycle and corresponding seasonal LAI variation and magnitudes compared to control simulations (Fig. 3). In addition, the temporal pattern of energy fluxes and NEE were improved with CLM_WW compared to the control run.

In general, CLM_WW yielded LAI peak magnitudes similar to observations at the sites BE-Lon, DE-RuS, and DERuM (Fig. 3). For DE-Kli, site-specific observations of the LAI were not available, but simulated LAI magnitudes for DE-Kli using CLM_WW are similar to those for BE-Lon. For the BE-Lon site, CLM_WW-simulated peak LAI magnitudes are close to the observations. An exception is the year 2015, where CLM_WW underestimated the unusually high LAI values observed in May and June, which ranged from 5.40 to $6.38 \mathrm{~m}^{2} \mathrm{~m}^{-2}$. For BE-Lon, faster growth was simulated in the early growing stage of winter wheat, resulting in a more gradual increase in LAI compared to the other sites (Fig. 3). This is related to higher air temperatures at BE-Lon 


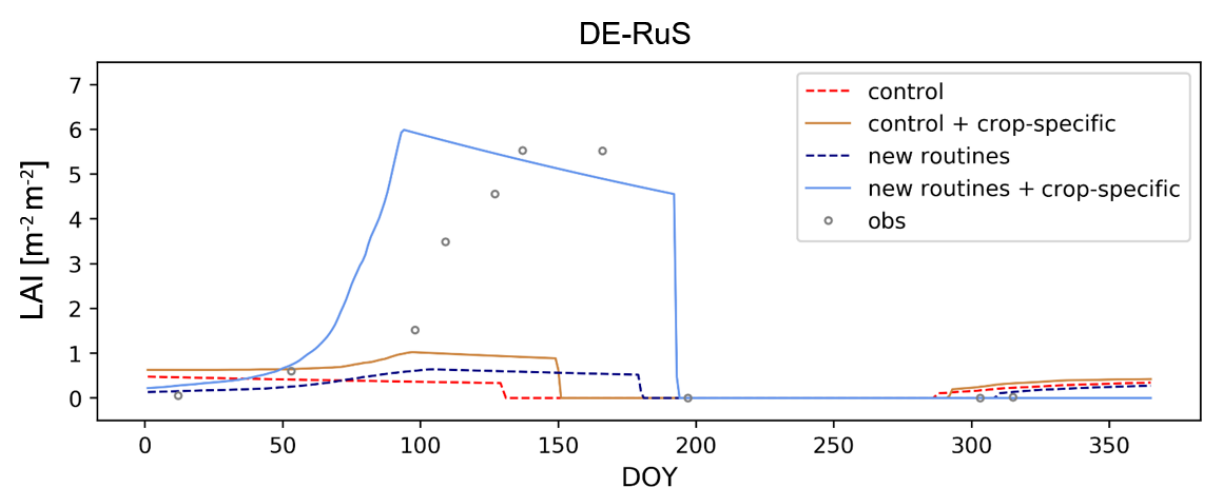

Figure 2. Daily simulation results for the LAI, simulated with default model and the default parameter set (control), the default model with new parameter set (control + crop-specific), the extended winter wheat model with default parameterization (new routines), and the extended model with the new parameter set (new routines + crop-specific), compared to point observations for a winter wheat year at DE-RuS.

early in the growing stage (especially in February) that enabled more simulated growth compared to the other sites.

Overall, the LAI peak simulated with CLM_WW occurred about 1 month earlier than observed, suggesting that maturation was reached too early. This is also reflected in the simulated CLM_WW harvest dates that are approximately 1 month earlier than the recorded dates (Table 3). While the planting date is the same for the control run and the CLM_WW simulations, CLM_WW generally resulted in a better match of simulated and recorded harvest dates (1.5 to 2 months later than control run).

The correlation of simulated grain yield and site records was significantly improved by up to $87 \%$ in CLM_WW simulations compared to the control run. At the DE-RuS site, CLM_WW resulted in a grain yield of $9.15 \mathrm{tha}^{-1}$ that is very close to the observed value of $9.2 \mathrm{tha}^{-1}$, while grain yield is strongly underestimated in the control run $\left(1.17 \mathrm{tha}^{-1}\right)$. For DE-Kli, the CLM_WW-simulated crop yield matched the recorded yield data very well for the year 2016 and was overestimated for 2011 by approximately $16 \%$. The control run resulted in an underestimation of yield by more than $80 \%$ (Fig. 4, Table 3). For BE-Lon the simulated crop yield is underestimated compared to site harvest records (Fig. 4, Table 3). While CLM_D simulations underestimated the grain yield by approximately $85 \%-90 \%$, CLM_WW underestimated yield by only $18 \%-36 \%$ at BE-Lon. The simulated yields by CLM_WW for the individual years show only minimal variations with values from 8.12 to $8.16 \mathrm{tha}^{-1}$, while the measured yields ranged from 9.92 to $12.88 \mathrm{tha}^{-1}$, indicating that CLM did not capture the inter-annual yield variation very well (Table 3).

Overall, the better representation of the winter wheat growing cycle by CLM_WW can also be inferred from the simulated surface energy fluxes (Fig. 3). In terms of net radiation, both CLM_WW and the control run are very close to the observations (Table 4). However, CLM_WW was able to better capture seasonal variations of surface energy fluxes during the growing cycle of the crop (Fig. 3). The correla- tion coefficients for the energy fluxes (LE, $H$ and Rn) calculated over the period from planting to harvest date for daily simulation results and daily observation data improved for all sites (Table 4). The highest correlations were reached for the sites DE-Kli with $r$ values of 0.62 and 0.71 and for BELon with $r$ values of 0.5 and 0.46 for sensible heat and latent heat flux, respectively (Table 4). Due to the simulated LAI peak being too early, latent heat flux is underestimated by CLM_WW (Fig. 3, Table 4). The high latent heat fluxes measured at BE-Lon and DE-Kli in the later months of the year (from day 220 onwards) reflect the growth of a cover crop. At both the BE-Lon site and at the DE-Kli site, cover crops are typically sown after harvest of winter wheat (mustard at BE-Lon, radish and brassica at DE-Kli), and they strongly affect surface energy fluxes later in the year. In contrast, in the control simulations and CLM_WW, the crop fields were simulated as fallow after the harvest of winter wheat (Fig. 3, Table A1). While the correlation of the latent and sensible heat flux during the growing cycle of the crop is generally increased with the CLM_WW model, the overall annual correlation is still relatively poor due to the influence of cover cropping and poor representation of post-harvest field conditions (annual performance metrics are included in the Supplement, Table S3). Furthermore, CLM_WW was generally better able to match NEE observations compared to control runs, partly due to the better representation of the seasonal LAI variations (Fig. 3). During the growing season of winter wheat, the negative peak in NEE coincides with the peak in LAI. Negative NEE values indicate a carbon sink and happen when the crop gains more carbon through photosynthesis than is lost through respiration. Correlation improved (comparing CLM_WW to the control run) from 0.13 to 0.46 for BE-Lon, from 0.21 to 0.33 for DE-RuS and from 0.29 to 0.56 for DE-Kli. The resulting correlation for CLM_WW simulations is still relatively low due to an underestimation of the cumulative monthly NEE during seasons with high NEE at BE-Lon and DE-RuS. For DE-Kli, CLM_WW was able to match NEE observed at peak LAI very well, but late sea- 

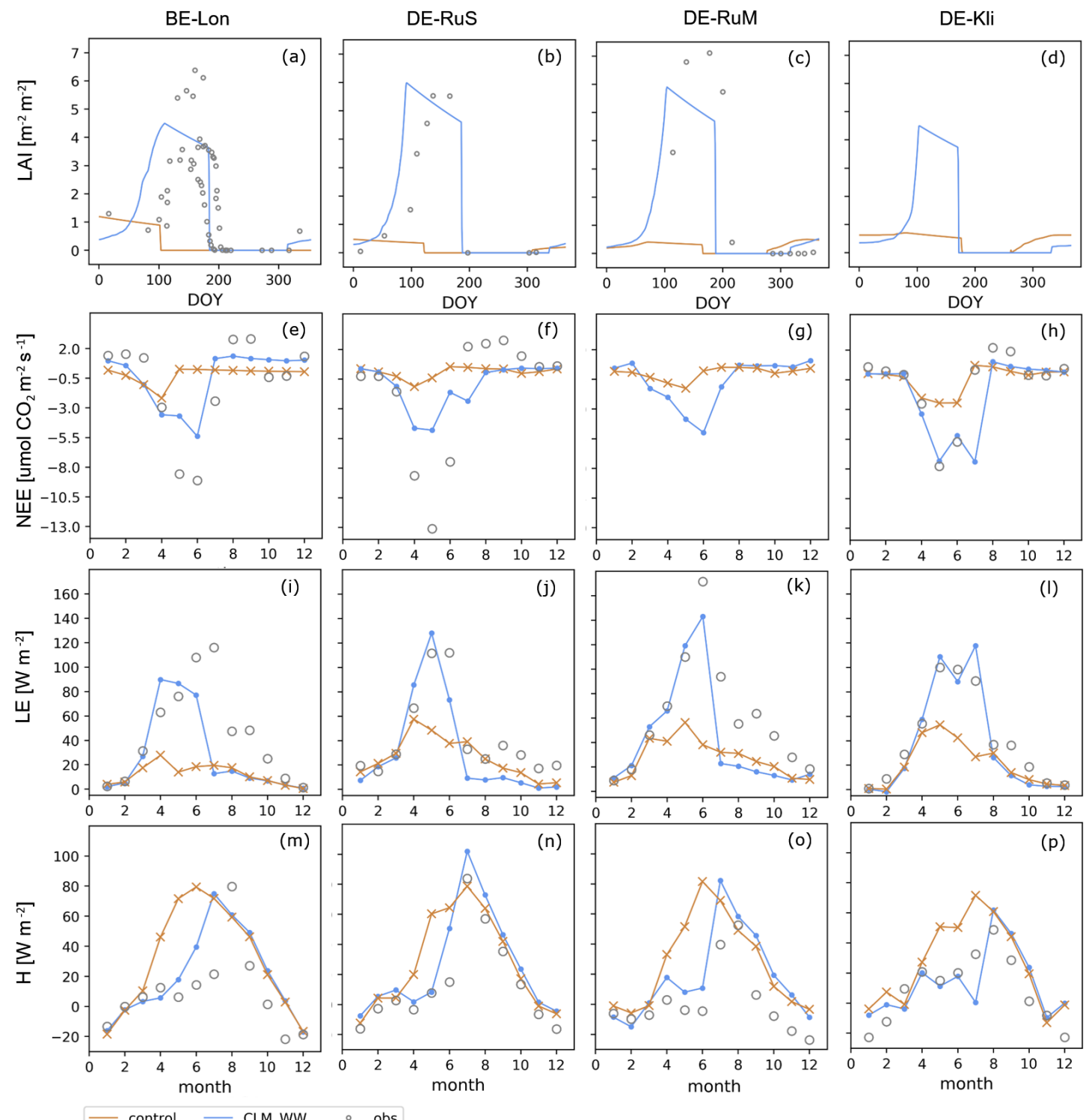

Figure 3. Simulation results of (a-d) LAI, and simulation results averaged for each month of (e-h) NEE, (i-l) LE, and (m-p) $H$ for all winter wheat years (see Table 3) at the sites (from left to right) BE-Lon, DE-RuS, DE-RuM, and DE-Kli. Simulation results from the new routine with crop-specific parameterization (CLM_WW; blue) are compared to control simulations (orange) and available site observations (grey) of LAI (all available point observations plotted) and fluxes (averaged over all respective years and for each month, respectively). Corresponding performance statistics for daily simulation results during the crop growth cycle are listed in Table 4.

sonal NEE (July) shortly before harvest is overestimated by CLM_WW, resulting in a low overall agreement with observation data. Furthermore, post-harvest field observations at BE-Lon, DE-RuS, and DE-Kli indicate that heterotrophic respiration from soil organic matter and litter results in a carbon source that is not simulated well in CLM (no GPP, nearzero NEE) (Fig. 3). This poor representation of post-harvest field conditions is reflected in low correlations over the whole year (Table S3).

\subsection{Crop-specific parameterization of sugar beet and potatoes}

The crop-specific parameter sets were tested for several years with sugar beet and potato planting at BE-Lon and DE-RuS, respectively. The performance in reproducing seasonal variations and magnitudes of energy fluxes was strongly improved with the crop-specific parameterization. Correspondingly, simulations with the crop-specific parameter sets for both sugar beet and potatoes were able to reasonably capture seasonal variations and peak values of LAI and growth cycle 


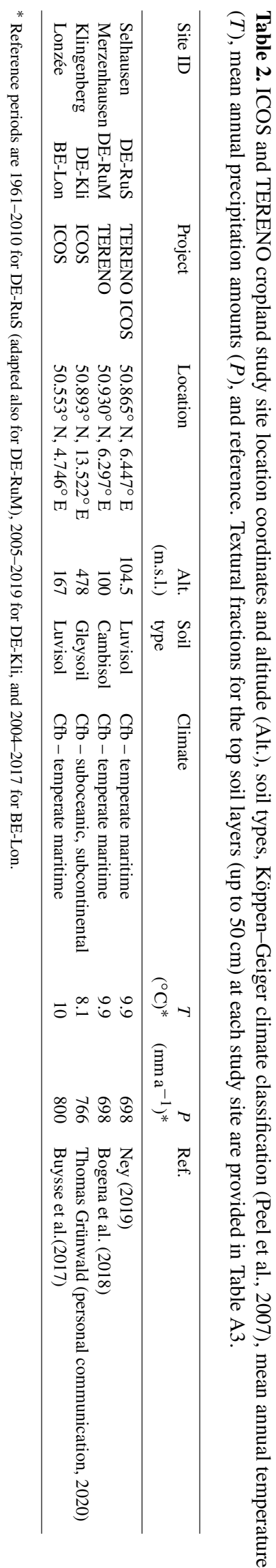

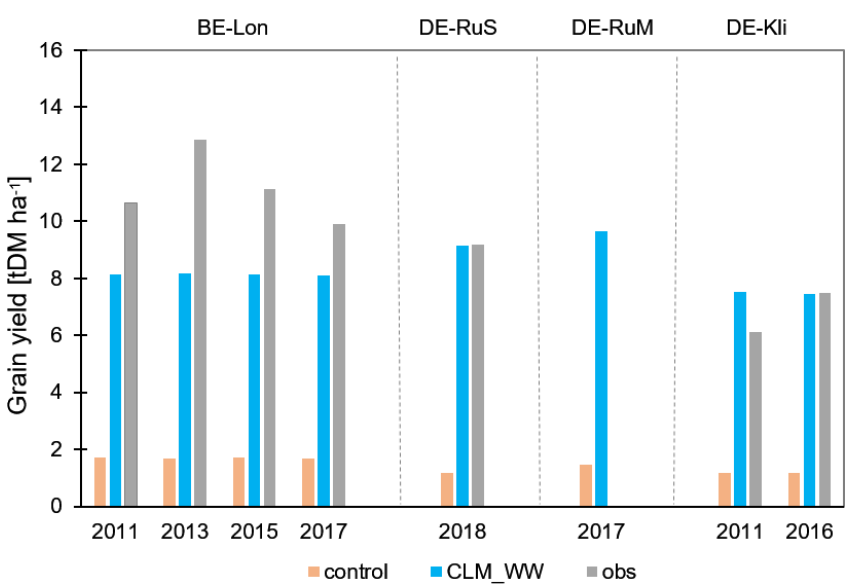

Figure 4. Annual grain yield $\left(\mathrm{tDM} \mathrm{ha}^{-1}\right)$ simulated with the control run (orange) and the extended winter wheat model with cropspecific parameterization (blue), compared to recorded harvest yields (grey) for all simulated winter wheat years (indicated on the $x$ axis) at the sites BE-Lon, DE-RuS, DE-RuM, and DE-Kli.

length and harvest time (Figs. 5, 6). The control run in CLM uses the spring wheat parameterization for these crop types and therefore reproduced the growth cycle and seasonal LAI of spring wheat, while simulations using the crop-specific potato and sugar beet parameterizations better captured harvest date and growth cycle of these crops.

The improved growth cycle representation with cropspecific parameters also led to more accurate simulation of energy fluxes. For sugar beet at BE-Lon, the latent heat flux at peak LAI corresponds well with observed values while being underestimated before and after peak LAI, and hence the sensible heat flux is overestimated at these times (Fig. 5). Seasonal variations of energy fluxes and magnitudes were also captured much better in simulations with the new parameterization. The simulations with crop-specific parameters show slightly better net radiation correlations for both the sugar beet and potato CFTs at each site, compared to the control run (Table 5). The correlation between simulated and observed latent heat flux for sugar beet was strongly improved by changing the parameters ( 0.11 to 0.55 for DE-RuS and 0.21 to 0.55 for BE-Lon). The same is true for the simulated sensible heat flux for sugar beet ( 0.04 to 0.76 for DE-RuS and 0.08 to 0.51 for BE-Lon). The NEE for the sugar beet CFT is underestimated during peak LAI periods in the control run, resulting in poorer correlations compared to latent and sensible heat flux and net radiation (Fig. 5). Simulations with the crop-specific parameter set resulted in a reduction in negative bias for NEE and reached higher correlation compared to the control simulation ( 0.03 to 0.37 for DE-RuS and 0.05 to 0.64 for BE-Lon).

Similar improvements can be observed for the new potato parameterization, while the correlation of simulation results with observation data is generally lower compared to the 
SUGAR BEET
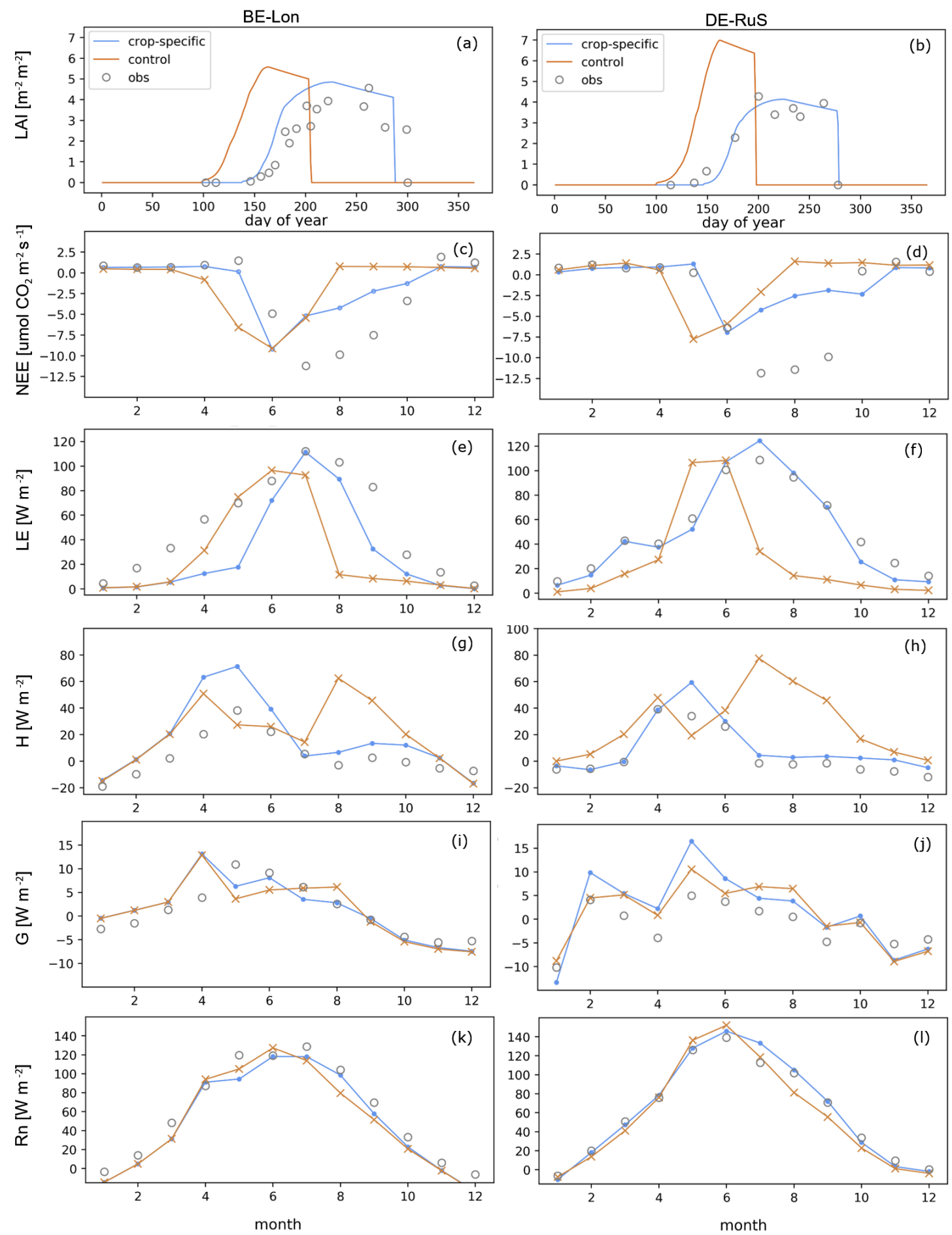

Figure 5. Simulation results of (a-b) LAI, and monthly averaged simulation results of (c-d) NEE, (e-f) LE, (g-h) $H$, (i-j) $G$, and (k-l) Rn for all sugar beet years (see Table 5) at the sites (left) BE-Lon and (right) DE-RuS. Simulation results for the control run (orange) and the crop-specific parameter set (blue) are compared to available site observations (grey) of LAI (all available point observations plotted) and fluxes (averaged over all respective years). Corresponding performance statistics for daily simulation results are listed in Table 5. 
POTATOES
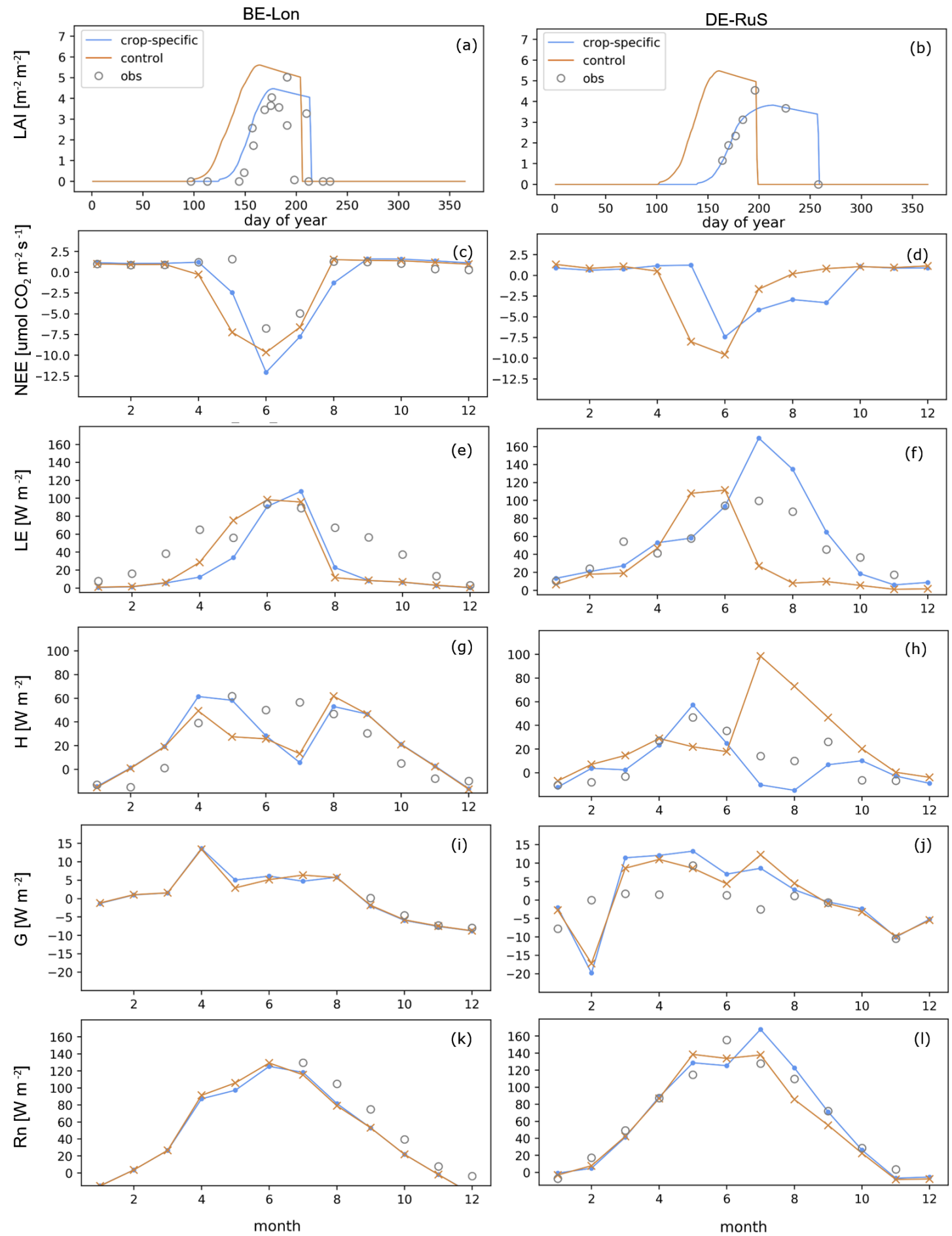

Figure 6. Simulation results of (a-b) LAI and monthly averaged simulation results of (c-d) NEE, (e-f) LE, (g-h) $H$, (i-j) $G$, and (k-l) Rn for all potato years (see Table 5) at the sites (left) BE-Lon and (right) DE-RuS. Simulation results for the control run (orange) and the crop-specific parameter set (blue) are compared to available site observations (grey) of LAI (all available observations plotted) and fluxes (averaged over all respective years). Corresponding performance statistics for daily simulation results are listed in Table 5. 
Table 3. Simulated annual planting and harvest dates and grain yield ( $\mathrm{tDM} \mathrm{ha}^{-1}$ ) by CLM_WW and CLM_D simulations (calculated using the peak daily grain carbon throughout the growth cycle) compared to recorded harvest dates and grain yield (Obs) for all simulated winter wheat years at the sites BE-Lon, DE-RuS, DE-RuM, and DE-Kli. For CLM simulation results, grain yield is calculated from grain carbon, which is assumed to be $45 \%$ of the total dry weight.

\begin{tabular}{|c|c|c|c|c|}
\hline Year & Source & $\begin{array}{r}\text { Planting date } \\
\text { (DD.MM.YYYY) }\end{array}$ & $\begin{array}{r}\text { Harvest date } \\
\text { (DD.MM.YYYY) }\end{array}$ & $\begin{array}{r}\text { Grain yield } \\
{\left[\mathrm{tDM} \mathrm{ha}^{-1}\right]}\end{array}$ \\
\hline \multicolumn{5}{|l|}{ BE-Lon } \\
\hline \multirow[t]{3}{*}{$2010 / 2011$} & CLM_D & 11.09 .2010 & 10.05 .2011 & 1.71 \\
\hline & CLM_WW & 11.09 .2010 & 05.07.2011 & 8.14 \\
\hline & Obs & 14.10 .2010 & 16.08.2011 & $10.64^{*}$ \\
\hline \multirow[t]{3}{*}{$2012 / 2013$} & CLM_D & 12.09 .2012 & 19.04 .2013 & 1.68 \\
\hline & CLM_WW & 12.09 .2012 & 25.06 .2013 & 8.16 \\
\hline & Obs & 25.10 .2012 & 12.08 .2013 & 12.88 \\
\hline \multirow[t]{3}{*}{$2014 / 2015$} & CLM_D & 09.09 .2014 & 20.04 .2015 & 1.71 \\
\hline & CLM_WW & 09.09 .2014 & 01.07 .2015 & 8.15 \\
\hline & Obs & 15.10 .2014 & 02.08 .2015 & 11.13 \\
\hline \multirow[t]{3}{*}{$2016 / 2017$} & CLM_D & 11.09 .2016 & 02.05 .2017 & 1.68 \\
\hline & CLM_WW & 11.09 .2016 & 24.07.2017 & 8.12 \\
\hline & Obs & 29.10 .2016 & 30.07 .2017 & 9.92 \\
\hline \multicolumn{5}{|l|}{ DE-RuS } \\
\hline \multirow[t]{3}{*}{$2017 / 2018$} & CLM_D & 29.09 .2017 & 17.05.2018 & 1.17 \\
\hline & CLM_WW & 29.09 .2017 & 27.06.2018 & 9.15 \\
\hline & Obs & 25.10 .2017 & 16.07 .2018 & 9.2 \\
\hline \multicolumn{5}{|l|}{ DE-RuM } \\
\hline \multirow[t]{3}{*}{$2016 / 2017$} & CLM_D & 27.09.2016 & 15.05 .2017 & 1.45 \\
\hline & CLM_WW & 27.09.2016 & 30.06 .2017 & 9.65 \\
\hline & Obs & 17.10 .2016 & 22.07 .2017 & - \\
\hline \multicolumn{5}{|l|}{ DE-Kli } \\
\hline \multirow[t]{3}{*}{$2010 / 2011$} & CLM_D & 15.09 .2009 & 23.07.2011 & 1.19 \\
\hline & CLM_WW & 15.09.2009 & 11.08 .2011 & 7.53 \\
\hline & Obs & 02.10 .2010 & 22.08.2011 & 6.12 \\
\hline \multirow[t]{3}{*}{$2015 / 2016$} & CLM_D & 17.09 .2015 & 24.07.2016 & 1.17 \\
\hline & CLM_WW & 17.09 .2015 & 28.07.2016 & 7.44 \\
\hline & Obs & 18.09 .2015 & 24.08 .2016 & 7.48 \\
\hline
\end{tabular}

* Grain yield estimated from $18.09 \mathrm{tha}^{-1}$ total biomass (stem and ear) yield according to stem and ear (grain) biomass yield ratios measured for other winter wheat years at the same site.

sugar beet CFT (Fig. 6, Table 5). Seasonal LAI variations, growing cycle length, and corresponding energy flux variations are improved in simulations with the new parameter set. Both the latent and the sensible heat flux are strongly improved at DE-RuS with correlation coefficients of 0.54 and 0.45 for CLM_WW simulations, respectively. For BE-Lon, the improvement in correlation is slightly lower for both latent and sensible heat flux compared to DE-RuS. The seasonal variation of the NEE at BE-Lon is reasonably captured, while monthly sums are overestimated with both parameterizations. Simulations of the NEE using the crop-specific parameter set yielded a slightly better correlation of $0.58 \mathrm{com}$ pared to the control simulation that resulted in a correlation of 0.43 (Table 5).

\subsection{Cover-cropping and crop rotation schemes}

The cover-cropping scheme was tested for two fields of application: (1) simulation of a cover crop as a second crop growth onset within a single year and (2) a more flexible crop rotation between different cash crops. In this step, simulations were run with the previously tested crop-specific parameterizations for sugar beet, potatoes, and winter wheat, and results were again compared to a control simulation run, where a consecutive growth of spring wheat is simulated.

To test the first application of the cover-cropping and crop rotation schemes, we simulated the cash crop and cover crop rotation cycle at DE-RuS from 2016 to 2017 (Fig. 7). A greening mix was planted as a cover crop in between the cash 
Table 4. Bias, root-mean-square error (RMSE), and Pearson correlation coefficient ( $r$ ) for the control run and CLM_WW-simulated daily NEE ( $\left.\mu \mathrm{mol} \mathrm{CO}_{2} \mathrm{~W} \mathrm{~m}^{-2} \mathrm{~s}^{-1}\right)$, LE $\left(\mathrm{W} \mathrm{m}^{-2}\right), \mathrm{H}\left(\mathrm{W} \mathrm{m}^{-2}\right)$, and $\mathrm{Rn}\left(\mathrm{W} \mathrm{m}^{-2}\right)$ at the sites BE-Lon, DE-RuS, DE-RuM, and DE-Kli. Values were calculated over the time period between recorded planting and harvest dates (averaged over all winter wheat years at each site) using simulation output and observation data at a daily time step.

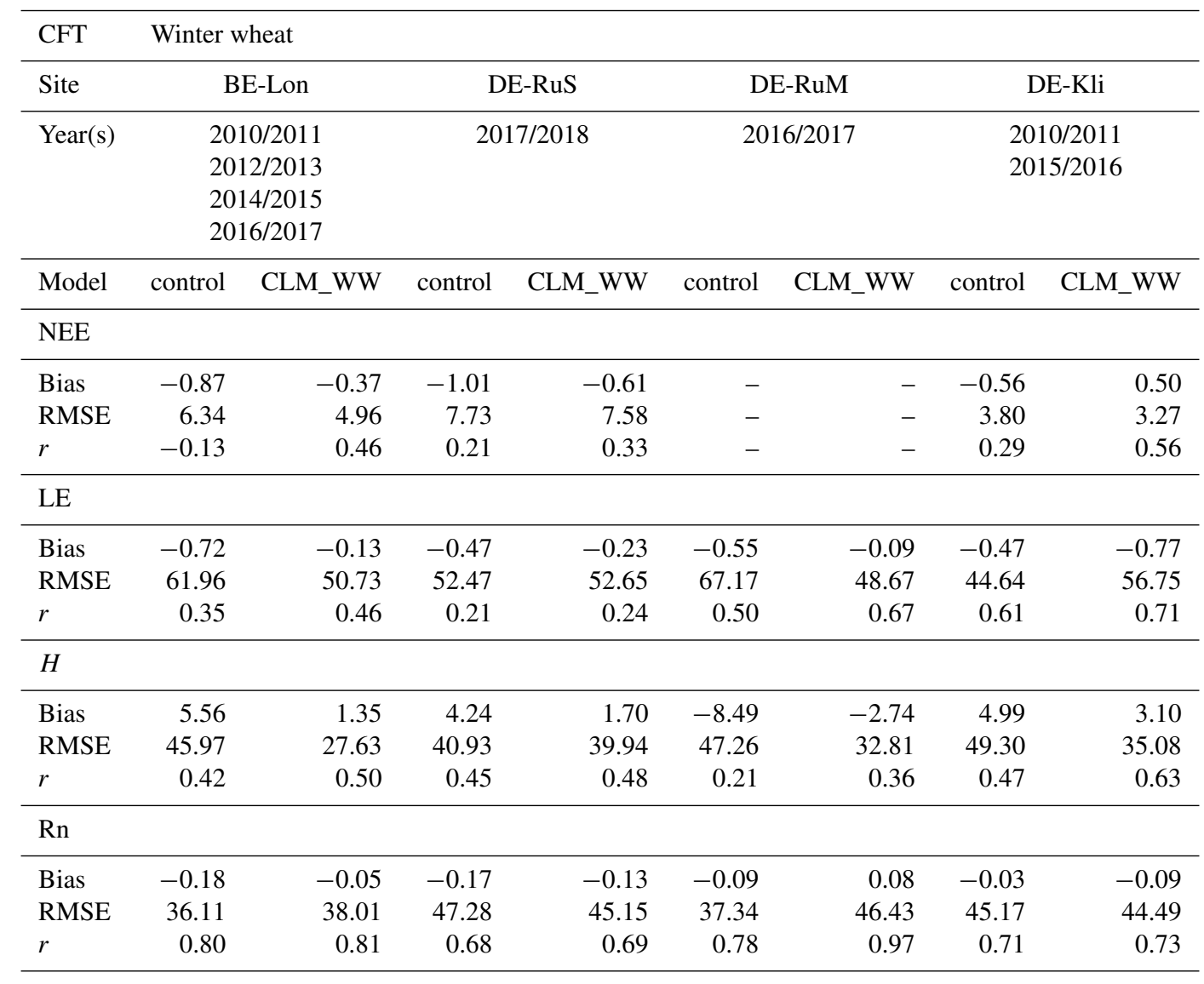

crop rotation of barley (simulated using the spring wheat CFT) in 2016 and sugar beet in 2017. While only a consecutive growth cycle of spring wheat is simulated in the control run, the new routine was able to represent the crop rotation from barley to sugar beet in the following year as well as a cover crop in between the cash crop cycles. Both the simulation of a cover crop and the rotation of cash crops strongly improved the representation of LAI in simulations with the new routine over multiple years, especially during winter months (Figs. 7, 8). While in control simulations the model assumed bare field conditions with no plant growth (LAI of 0 ) and very low latent heat flux, the new routine simulated the planting of a cover crop in fall of 2016, which leads to an increase in latent heat flux related to increased transpiration. Statistical evaluation of the simulated latent heat flux for the time window after harvest of the first cash crop from August 2016 to April 2017 shows that with the new routine the negative bias was reduced from 0.74 to 0.13 compared to control simulation results, resulting in an RMSE reduction by approximately $42 \%$ (Fig. 7).
For the second case (DE-RuS), which represents a higher flexibility towards cash crop rotation, we simulated the years of 2017 to 2019. Here, the crop rotation switched from sugar beet in 2017 to winter wheat in 2017/2018 and potatoes in 2019 (Fig. 8). In the control simulation, using the default CLM5 phenology algorithm, a consecutive cycle of spring wheat is simulated. The new routine was able to represent the rotation between different cash crops on the same field. This resulted in a much better correspondence of simulated LAI cycle and magnitudes with observations compared to control simulations. Statistical analysis of the latent heat flux showed an improvement of the RMSE (calculated for daily simulation output and observation data over these three years) from 43.74 to 32.94 and the correlation coefficient from 0.40 to 0.63 with the new routine. The improvement in simulated energy fluxes for each CFT individually is in accordance with the results presented in the previous chapters (Sect. 4.1 and 4.2). 
Table 5. Bias, root-mean-square error (RMSE), and Pearson correlation coefficient $(r)$ for the simulated daily $\mathrm{NEE}\left(\mu \mathrm{mol} \mathrm{CO} \mathrm{W} \mathrm{m}^{-2} \mathrm{~s}^{-1}\right)$, $\mathrm{LE}\left(\mathrm{W} \mathrm{m}^{-2}\right), H\left(\mathrm{~W} \mathrm{~m}^{-2}\right)$, and $\mathrm{Rn}\left(\mathrm{W} \mathrm{m}^{-2}\right)$ using the crop-specific parameterization (specific) for the CFTs sugar beet and potatoes at the sites BE-Lon and DE-RuS, respectively. Results are compared to those from the control simulation runs (control). Values were calculated over the time period between recorded planting and harvest dates (averaged over all respective CFT years at each site) using simulation output and observation data at daily time step.

\begin{tabular}{|c|c|c|c|c|c|c|c|c|}
\hline \multirow{4}{*}{$\begin{array}{l}\text { CFT } \\
\text { Site } \\
\text { Year(s) } \\
\text { Parameter set }\end{array}$} & \multicolumn{4}{|c|}{ Sugar beet } & \multicolumn{4}{|c|}{ Potatoes } \\
\hline & \multirow{2}{*}{\multicolumn{2}{|c|}{$\begin{array}{c}\text { DE-RuS } \\
2017\end{array}$}} & \multicolumn{2}{|c|}{ BE-Lon } & \multirow{2}{*}{\multicolumn{2}{|c|}{$\begin{array}{c}\text { DE-RuS } \\
2019\end{array}$}} & \multicolumn{2}{|c|}{ BE-Lon } \\
\hline & & & \multirow{2}{*}{$\begin{array}{l}2008 \\
\text { control }\end{array}$} & \multirow{2}{*}{$\begin{array}{r}2016 \\
\text { specific }\end{array}$} & & & \multicolumn{2}{|c|}{$2010 \quad 2014 \quad 2018$} \\
\hline & control & specific & & & control & specific & control & specific \\
\hline \multicolumn{9}{|l|}{ NEE } \\
\hline Bias & -0.59 & -0.75 & 0.05 & -0.05 & - & - & 19.73 & 19.56 \\
\hline RMSE & 9.1 & 5.94 & 6.19 & 3.75 & - & - & 5.24 & 5.21 \\
\hline$r$ & -0.03 & 0.37 & 0.05 & 0.64 & - & - & 0.43 & 0.58 \\
\hline \multicolumn{9}{|l|}{ LE } \\
\hline Bias & -0.32 & 0.01 & -0.37 & -0.35 & -0.28 & 0.25 & 0.26 & 0.09 \\
\hline RMSE & 58.44 & 24.47 & 60.09 & 48.31 & 60.94 & 50.58 & 43.41 & 40.05 \\
\hline$r$ & 0.11 & 0.55 & 0.21 & 0.55 & 0.01 & 0.54 & 0.5 & 0.53 \\
\hline \multicolumn{9}{|l|}{$H$} \\
\hline Bias & 1.65 & 0.45 & 1.73 & 1.61 & 1.01 & -0.38 & 0.5 & 0.22 \\
\hline RMSE & 42.77 & 17.24 & 39.75 & 33.45 & 51.61 & 29.9 & 34.06 & 31.17 \\
\hline$r$ & -0.04 & 0.76 & -0.08 & 0.51 & -0.1 & 0.45 & 0.18 & 0.31 \\
\hline \multicolumn{9}{|l|}{$\mathrm{Rn}$} \\
\hline Bias & -0.02 & 0.04 & -0.11 & -0.11 & -0.04 & 0.04 & - & - \\
\hline RMSE & 19.74 & 15 & 37.47 & 35.87 & 48.39 & 49.88 & - & - \\
\hline$r$ & 0.5 & 0.51 & -0.22 & -0.22 & 0.56 & 0.57 & - & - \\
\hline
\end{tabular}

\section{Discussion}

All three modifications that were implemented in this study helped to improve the representation of cropland sites in CLM5. Similar to the findings of $\mathrm{Lu}$ et al. (2017) for CLM4.5, the implementation of their winter wheat routine resulted in a significant improvement in representing the seasonal LAI variations and surface energy fluxes during winter wheat growth. Next to maize and rice, wheat is one of the most important international food crops and among the most important cash crops in Germany (22.8 Mt winter wheat yield in 2019 nationwide; Statista, 2020). In Germany and other western European countries, winter cereal varieties (e.g., winter rye, barley, and wheat) are more abundant than summer cereals due to climatic conditions (Palosuo et al., 2011; Semenov and Shewry, 2011; Thaler et al., 2012). With an average annual winter wheat yield of around $20 \mathrm{Mt} \mathrm{a}^{-1}$ for Germany, an improvement of $87 \%$ in simulated yield with CLM_WW compared to the default model (as observed at the DE-RuS site in 2018) could result in a difference of several tens of millions of metric tons in total predicted annual yield on a nationwide scale.
Despite the general improvement of winter wheat growth and yield simulated with the modified CLM_WW, there is still potential for further increasing the flexibility towards simulating different crop varieties and management practices. Due to the phenology algorithm of CLM5, a low simulated LAI can indicate a lower grain yield due to low biomass growth. Accordingly, the higher simulated LAI for the DERuS site was associated with a slightly higher simulated grain yield for DE-RuS compared to BE-Lon. However, this relationship is not reflected in the observations, as the measured grain yield is lower for DE-RuS compared to BE-Lon, although the observed LAI is higher for DE-RuS (Fig. 3, Table 3).

In CLM, there are several variables that influence the simulated crop yield, such as LAI cycle and peak, length of the leaf-emergence phase, harvest date, and water availability from the soil. Except for soil moisture, these variables are strongly correlated to the GDD scheme, which suggests that the simulated crop yield profoundly depends on the GDD. The high sensitivity of simulated yield in CLM towards GDD is not reflected in actual field observation, where crop yield depends on a multitude of factors, environmental conditions 


\section{COVER CROPPING}

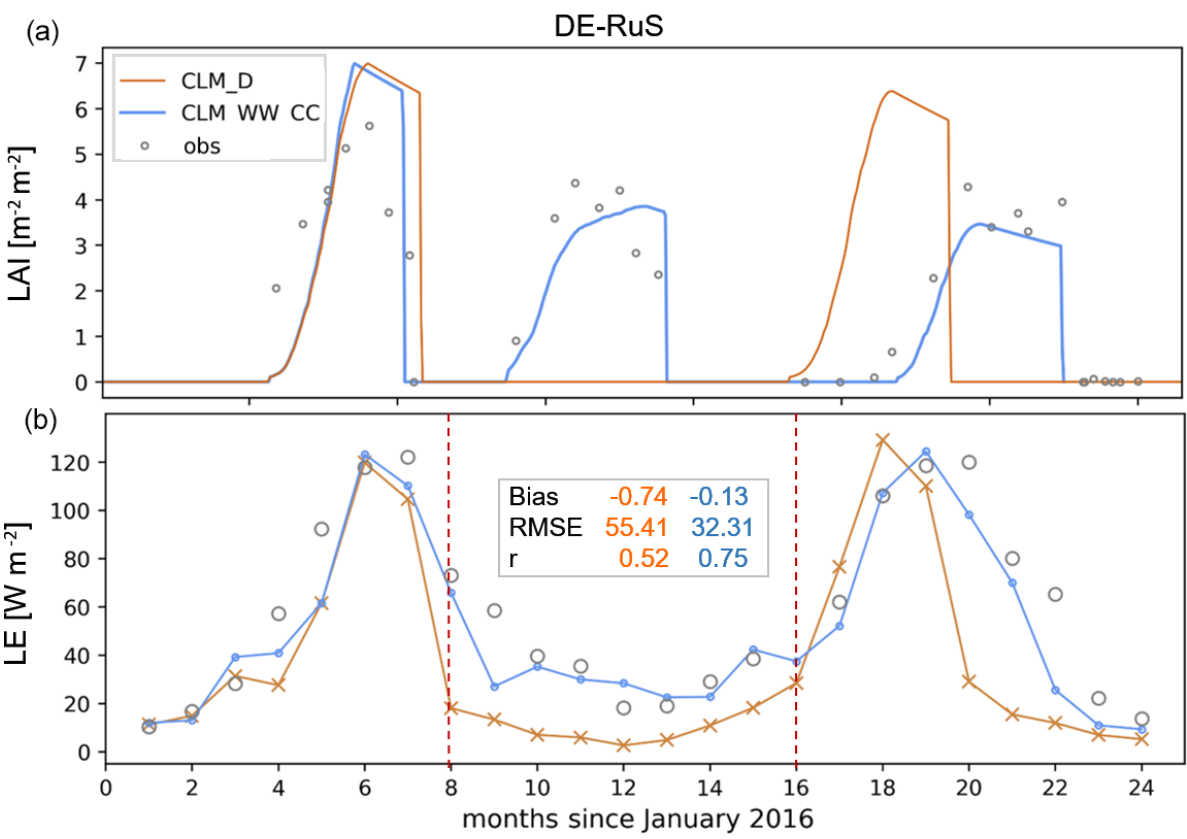

Figure 7. (a) Simulated LAI for cover cropping at DE-RuS with barley (2016), a greening mix cover crop (2016/2017), and sugar beet (2017) using the new cover-cropping subroutine (blue) in comparison to control simulation results with the default phenology algorithm of CLM5 (orange). (b) Corresponding monthly averaged simulation results for the latent heat flux with respective bias, RMSE, and $r$ for the time window are shown between the dashed red lines (calculated using simulation output and observation data at daily time step). Available observation data are plotted in grey.

\section{CROP ROTATION}
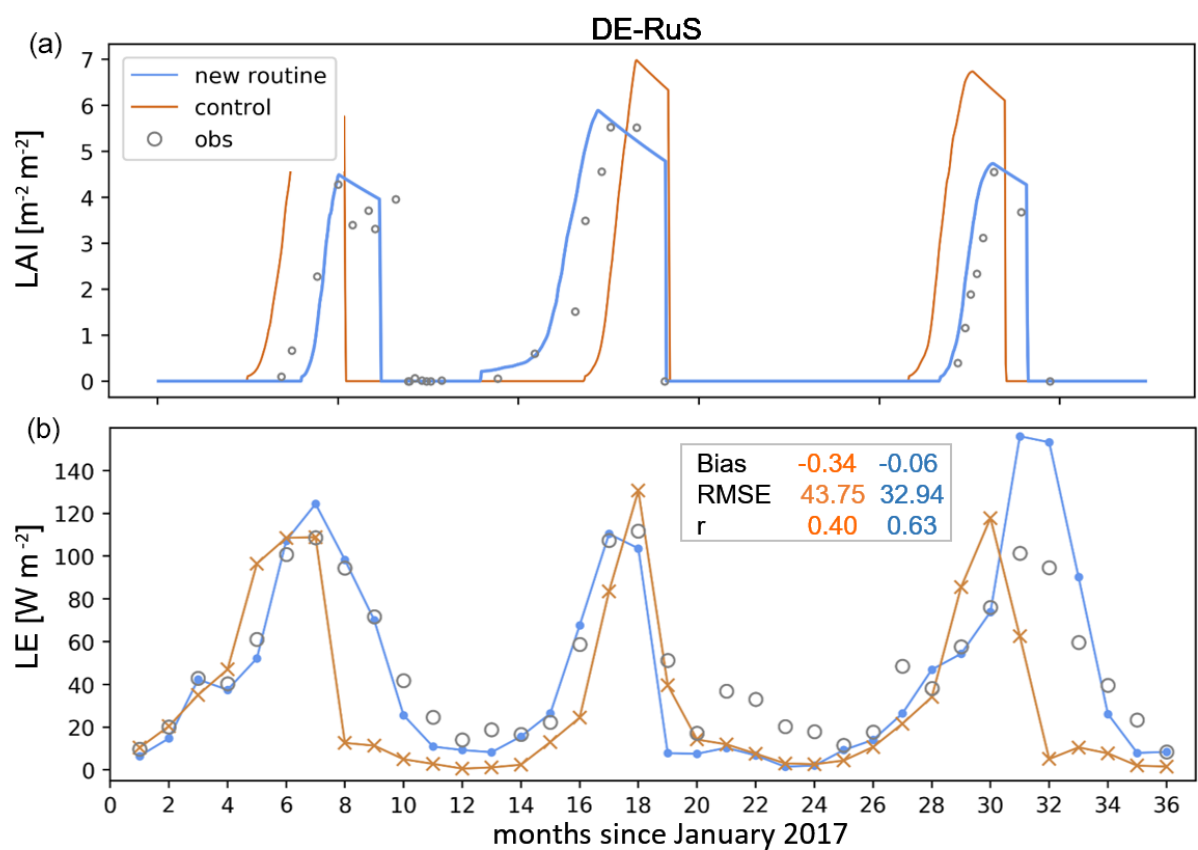

Figure 8. (a) Simulated LAI for crop rotation from sugar beet (2017), winter wheat (2017/2018), and potatoes (2019) at DE-RuS using the new cover-cropping subroutine (blue) in comparison to control simulation results with the default phenology algorithm of CLM5 (orange). (b) Corresponding monthly averaged simulation results for the latent heat flux with respective bias, RMSE, and $r$ over the whole time interval (calculated using simulation output and observation data at daily time step). Available observation data are plotted in grey. 
(weather, nutrient availability, atmospheric $\mathrm{CO}_{2}$ ), and management decisions. Underestimation of winter wheat yield at BE-Lon may be due to model deficiencies in representing the complex crop management practices, such as timing and type of fertilizer, plowing-crop varieties, and the usage of different winter wheat varieties that can show different responses to water or heat stress and frost and that have different grain productivities (White and Wilson, 2006; Bergkamp et al., 2018; Ceglar et al., 2019). In order to include different varieties of any crop, the list of CFTs could be extended with suitable plant parameterizations. However, this information is not readily available, due to a combination of measurement data scarcity and the complexity of the phenology algorithm and parameter scheme. The introduction of a phenology scheme based on plant physiological trait information in CLM could be a major improvement in this field (see Fisher et al., 2019) as plant trait information becomes more readily available (e.g., the TRY Plant Trait Database, Kattge et al., 2011). Whether considering different varieties and cultivars of a crop is important for regional- or global-scale simulations remains to be evaluated. In general, as already noted by Lu et al. (2017), a more process-based vernalization and cold-tolerance routine would be useful to make this subroutine more applicable to other winter crops like rapeseed.

The early leaf onset and harvest for winter wheat simulated by CLM (both with the new routine and parameter set and the control run) could be met by adjusting the minimum date for planting within the CFT parameterization. This could be useful to easily improve the crop cycle representation in regional simulations, where planting patterns are similar for larger agricultural areas. However it would restrict the flexibility of the model for prognostically simulating planting dates.

In general, the simulated plant growth and resulting yield were highly sensitive to plant parameters that govern the growing degree calculation, which in turn influence the phenological development and allocation of $\mathrm{C}$ and $\mathrm{N}$. With only a limited number of CFTs in CLM, a discretization of plant parameters or varieties on a regional scale is not possible at this point. A potential solution, without introducing additional CFTs, could be to account for key parameters for each CFT varying with climate and soil conditions for largescale simulations (e.g., by gridded parameter sets). Furthermore, there is a need to evaluate and further discretize plant hydraulic properties (at this point one set of hydraulic parameters is applied to all types of crops) (Verhoef and Egea, 2014; Kennedy et al., 2017; Kennedy et al., 2019). Within the crop module of CLM5, the carbon allocation of crops is limited by soil water available to the plant. Thus, both an improved soil hydrology and an improved representation of plant hydraulics could play a major role in improving the quality of yield prediction by the model (Bassu et al., 2014; Kennedy et al., 2019). These plant hydraulic properties could be estimated by inverse modeling or data assimilation (e.g., by assimilating measurement data like NEE, LAI, soil mois- ture, and/or energy fluxes using an augmented state vector approach). In addition, data assimilation of, e.g., in situ or remotely sensed soil moisture data and/or LAI, could play a major role in increasing the accuracy of regional yield predictions (e.g., Guérif and Duke, 2000; Launay and Guerif, 2005; de Wit and van Diepen, 2007; Fang et al., 2008; Vazifedoust et al., 2009; Huang et al., 2015; Jin et al., 2018).

The default CLM5 does not account for the influence of weeds or cover crops and/or their litter on the carbon balance. There is a tool available for CLM5 that enables the simulation of transient land use and land cover changes (LULCC) (Lawrence et al., 2018). It was designed to simulate the effects of changing distributions of natural and crop vegetation, e.g., land use change from forest to agricultural fields, and also allows for changes in crop type between years (Lawrence et al., 2018) but does not account for intra-annual changes of agricultural management on crop-vegetated areas that happen in double- and triple-cropping scenarios. While this tool is useful to study general land use changes by changing the land cover type of individual land units, we found it lacks flexibility in accounting for changes within land units of the same land cover and does not account for all 64 CFTs. Furthermore, this tool changes the CFT of each column on 1 January every year according to prescribed values (customized). Thus, when using the CLM5 land-use change tool, for example to simulate the crop rotation from sugar beet in 2017 to winter wheat in 2017/2018 at DE-RuS, winter wheat would not be planted before fall of 2018 (rather than in the same year as sugar beet is harvested) resulting in a long period of fallow field when switching from summer to winter crop (Fig. 8). Here, the implementation of our covercropping routine enabled a second onset of plant growth within a year (including the switch to another CFT). This resulted in a pronounced improvement in LAI curves and latent heat flux, especially during winter months, by simulating the growth of a cover crop. It also proved to be beneficial in representing realistic agricultural field conditions by allowing crop rotations with higher flexibility than the default model.

This new routine can be used to study cover-cropping scenarios in future large-scale simulations. The effect of a cover crop during winter months on all crop land units where cash crops are grown in summer could be tested. This could also be tested for specific cash crops only. In addition, it is possible to simulate cover crop plantations based on harvest date thresholds. A defined maximum harvest date for any specific cash crop could define whether a cover crop such as winter wheat would be planted or not. For example, for all sugar beet land units with harvest dates before a certain threshold (e.g., day 290 of any given year) winter wheat could be planted as a cover crop during winter. If this harvest threshold was not reached and the summer crop is harvested late in the year, no cover crop would be planted. Alternatively, these harvest thresholds could define the type of cover crop, e.g., early harvest - winter wheat, late harvest - simple greening mix. In addition, historical land use information could 
be used to simulate realistic cover-cropping and crop rotation scenarios. The succession of different crops from historical data could also be used to model the succession of crops for the future. In order to study large-scale effects of cover cropping and common crop rotations, the CLM5 model would greatly benefit from further crop-specific parameter sets for cover crops such as mustard and further important cash crops.

In their approach, Lombardozzi et al. (2018) studied the effects of idealized cover crop scenarios by simulating winter crops in all crop regions throughout North America. They found that the effects of cover crops on winter temperatures are strongly related to plant height and LAI and emphasized the importance of biogeophysical effects and varietal selection when evaluating the climate mitigation potential of cover cropping (Lombardozzi et al., 2018). With our new routine, it is now possible to evaluate the biogeophysical effects of cover crops over longer timescales and in combination with typical cash crop rotations throughout agricultural areas. In addition, the ecological potential of different cover crop varieties could be evaluated. We anticipate that this modification will allow a more realistic representation of seasonal LAI in ecosystems where cover cropping and crop rotations are common management practices. The application of this routine is also of interest for areas with several cash crop cycles within a year like the multiple annual crop cycles in India and China (Biradar and Xiao, 2011; Li et al., 2014; Sharma et al., 2015). We see further development potential for this routine and corresponding data sets to account for typical crop rotations and cover-cropping scenarios for regional-scale simulations (e.g., EU regulations and goals for the adoption of cover crops for climate change mitigation; Smit et al., 2019).

\section{Conclusions}

The default CLM5 was extended by adopting the winter wheat representation of Lu et al. (2017); by including cropspecific parameterization for winter wheat, sugar beet, and potatoes; and by the addition of a cover-cropping subroutine that allows several growth cycles within 1 year. The model modifications were tested for the respective crops at four TERENO and ICOS cropland sites in Germany and Belgium, Selhausen (DE-RuS), Merzenhausen (DE-RuM), Klingenberg (DE-Kli), and Lonzée (BE-Lon), for multiple years. The main results drawn from this study are as follows.

The implementation of the winter wheat subroutines led to a significant simulation improvement in terms of energy fluxes, leaf area index, net ecosystem exchange, and crop yield (reduction of underestimation from $80 \%-90 \%$ to $18 \%-36 \%$ at test site BE-Lon, a good match for the test sites DE-RuS and DE-Kli in 2016, and a slight overestimation at test site DE-Kli in 2011).

The model performance was strongly improved with the crop-specific parameter sets for sugar beet and potatoes: sea- sonal variations and magnitudes of energy fluxes and LAI were better reproduced with RMSE reduction during the crop cycle by up to $57 \%$ for latent and $59 \%$ for sensible heat flux at test site DE-RuS.

In most cases the modification of CLM5 led to better reproduction of measured NEE at the test sites. However, the model showed a general weakness in reasonably simulating the NEE on agricultural fields, especially the peak value and post-harvest conditions.

The implementation of our cover-cropping routine enabled a second onset of plant growth within a year and thus was able to better capture realistic field conditions after harvest. Wintertime RMSE for latent heat flux was reduced by $42 \%$. In addition, a higher flexibility in terms of crop rotation is now possible with CLM5.

We anticipate that our implementation of the winter wheat representation and specified parameterization will markedly improve yield predictions at regional scale for regions with a high abundance of winter cereal varieties. The covercropping routine offers an improved basis on which to study the effects of large-scale cover-cropping on energy fluxes, soil water storage, and soil carbon and nitrogen pools, as well as to investigate the role of different cover crops as natural fertilizer in future studies with CLM5. A more realistic representation of post-harvest field conditions can play a crucial part in better representing the role of agriculture on regional and global energy and carbon fluxes and will be further developed and tested for regional-scale simulations in future studies.

Despite our improvements, there is still a need to further develop certain functionalities and specific routines regarding the crop representation and land management in CLM5 in order to achieve better model performance for agricultural land. The applicability of the routines to large-scale simulations would strongly benefit from additional crop-specific parameterizations for important cash and cover crops. A better representation of plowing and tillage also needs be included in future model versions in order to better account for the effects of cover crops on the terrestrial carbon cycle and their biogeochemical benefits.

Further general examples for improvements include (1) an improved representation of plant and soil hydrology that may be highly beneficial for yield predictions, (2) a more detailed representation of agricultural management practices (e.g., tillage, $\mathrm{C} / \mathrm{N}$ turnover, post-harvest surface conditions, and fertilizer types and applications), (3) tools to account for spatial variability in plant physiological parameters, and (4) the discretization of plant hydraulic properties as opposed to using one parametrization for all crops. 


\section{Appendix A: Winter cereal representation (extended)}

The temperature at the crown of the plant $\left(T_{\text {crown }}\right)$ is assumed to be slightly higher than the $2 \mathrm{~m}$ air temperature $\left(T_{2 \mathrm{~m}}\right)$ in winter when covered by snow and the same as the $2 \mathrm{~m}$ air temperature without snow cover. Within CLM5, it is calculated separately for temperatures below and above the freezing temperature $\left(T_{\mathrm{frz}}\right)$ :

$T_{\text {crown }}=2+\left(T_{2 \mathrm{~m}}-T_{\text {frz }}\right) \cdot(0.4+0.0018$

$$
\left.\cdot\left(\min \left(D_{\text {snow }} \cdot 100,15\right)-15\right)^{2}\right)
$$

for $T_{2 \mathrm{~m}}<T_{\mathrm{frz}}$

$T_{\text {crown }}=T_{2 \mathrm{~m}}-T_{\text {frz }}$

for $T_{2 \mathrm{~m}}>T_{\mathrm{frz}}$,

where $T_{\text {crown }}(\mathrm{K})$ is the calculated crown temperature, $T_{2} \mathrm{~m}$ $(\mathrm{K})$ is the $2 \mathrm{~m}$ air temperature, $T_{\mathrm{frz}}(\mathrm{K})$ is the freezing point and $D_{\text {snow }}(\mathrm{m})$ is the snow height.

The temperature at which $50 \%$ of the plant is damaged $\left(\mathrm{LT}_{50}\right)$ is calculated interactively at each time step $\left(\mathrm{LT}_{50 t}\right)$, depending on the previous time step $\left(\mathrm{LT}_{50 t-1}\right)$ and on several accumulative parameters. These parameters are the exposure to near-lethal temperatures $\left(\right.$ rate $\left._{\mathrm{S}}\right)$, the stress due to respiration under snow $\left(\right.$ rate $\left._{\mathrm{r}}\right)$, the cold hardening or lowtemperature acclimation (contribution of hardening: rate $_{h}$ ), and the loss of hardening due to the exposure to a period of higher temperatures (dehardening: rate $_{d}$ ) that are each functions of the crown temperature (Lu et al., 2017, and references therein):

$\mathrm{LT}_{50 t}=\mathrm{LT} 50 t-1-$ rate $_{\mathrm{h}}+$ rate $_{\mathrm{d}}+$ rate $_{\mathrm{s}}+$ rate $_{\mathrm{r}}$.

The exposure to near-lethal temperatures is based on the winter survival model of Fowler et al. (1999) and is calculated as follows:

rate $_{\mathrm{s}}=\frac{\mathrm{LT}_{50 t-1}-T_{\text {crown }}}{e^{-1.9\left(\mathrm{LT}_{50 t-1}-T_{\text {crown }}\right)-3.74}}$.

The stress due to respiration under snow is calculated as a function of snow depth (dsnow) that ranges from 0 to 1 for snow cover up to $12.5 \mathrm{~cm}$ (equal to 1 for all snow depth higher than 12.5) and a specific respiration factor (RE):

rate $_{\mathrm{r}}=R \cdot \mathrm{RE} \cdot f($ dsnow $)$

$R=0.54 f($ dsnow $)=\min ($ dsnow, 12.5$) / 12.5$

$\mathrm{RE}=\frac{e^{0.84+0.051 T_{\text {crown }}}-2}{1.85}$

The contribution of hardening and dehardening are calculated within certain temperature ranges as follows:

$$
\begin{aligned}
& \text { For } T_{\text {crown }}<10^{\circ} \mathrm{C} \\
& \text { rate }_{\mathrm{h}}=0.0093\left(10-\max \left(T_{\text {crown }}, 0\right)\right) \\
& \quad\left(\mathrm{LT}_{50 t-1}-\mathrm{LT}_{50 c}\right) .
\end{aligned}
$$

For $T_{\text {crown }} \geq 10^{\circ} \mathrm{C}$ when vf $<1$ (not fully vernalized) and $T_{\text {crown }} \geq-4^{\circ} \mathrm{C}$ when vf $=1$ (fully vernalized)

rate $_{\mathrm{d}}=2.7 \times 10^{-5}\left(\mathrm{LT}_{50 i}-\mathrm{LT}_{50 t-1}\right)\left(T_{\text {crown }}+4\right)^{3}$,

where $\mathrm{LT}_{50 c}$ is the maximum frost tolerance of $-23^{\circ} \mathrm{C}$ and $\mathrm{LT}_{50 i}$ represents the $\mathrm{LT}_{50}$ for an unacclimated plant $\left(\mathrm{LT}_{50 i}=\right.$ $\left.-0.6+0.142 \mathrm{LT}_{50 c}\right)$.

The survival rate $\left(f_{\text {surv }}\right)$ is then calculated as a function of $\mathrm{LT}_{50}$ and the crown temperature. The probability of survival is a function of $T_{\text {crown }}$ in time $(t)$. It increases once $T_{\text {crown }}$ is higher than $\mathrm{LT}_{50}$ and decreases when it is lower (Vico et al., 2014):

$f_{\text {surv }}\left(T_{\text {crown }}, t\right)=2^{-\frac{T_{\text {crown }} \alpha_{\text {surv }}}{L T_{50}}}$,

where $\alpha_{\text {surv }}$ is a shape parameter of 4 .

The winter killing degree day (WDD) is calculated as a function of crown temperature and survival probability, where the maximum function limits the integration to the potentially damaging periods when the air temperature $(T)$ is lower than the base temperature $\left(T_{\text {base }}\right)$ of $0^{\circ} \mathrm{C}$ (Vico et al., 2014):

$$
\begin{gathered}
\mathrm{WDD}=\int_{\text {winter }} \max \left[\left(T_{\text {base }}-T_{\text {crown }}\right), 0\right] \\
{\left[1-f_{\text {surv }}\left(T_{\text {crown }}, t\right)\right] \mathrm{d} t .}
\end{gathered}
$$

Lower $\mathrm{LT}_{50}$ indicates a higher frost tolerance and would result in higher survival rates, smaller WDD and less cold damage to the plant. Thus, when the survival probability and crown temperature are low, the WDD will be high (Vico et al., 2014).

The survival probability and the WDD are then used to estimate instant and accumulated frost damage to the crop during the leaf-emergence phase (Lu et al., 2017). Instant frost damage (especially to new leaves or small seedlings) is assumed to happen due to due to an exposure to low temperatures the beginning of the growing season when the plants are not fully vernalized ( $\mathrm{vf}<0.9)$. It is simulated by reducing the leaf carbon at low survival probabilities (whenever $f_{\text {surv }}$ is below 1). The leaf carbon is reduced by an amount of $5 \mathrm{gC} \mathrm{m}^{-2}$, scaled by a factor of $1-f_{\text {surv }}$, which is moved to the carbon litter pool, up to a minimum value of $10 \mathrm{gC} \mathrm{m}^{-2}$ leaf carbon:

$$
\begin{aligned}
& \text { leafc }_{t}=\text { leafc }_{t-1}-\text { leafc }_{\text {damage }}\left(1-f_{\text {surv }}\right) \\
& \text { for vf }<0.9, \text { WDD }>0, f_{\text {surv }}<1, \text { and leafc } \\
& t>10,
\end{aligned}
$$

where leafc $c_{t}$ is the simulated leaf carbon of the current time step, leafc $t_{t-1}$ is the leaf carbon of the previous step, and leafc damage $_{\text {is equivalent to }} 5 \mathrm{gC} \mathrm{m}^{-2}$.

When the plant is close to vernalization towards the end of the leaf-emergence phase, it is not as susceptible to suffering from instantaneous frost damage as in the beginning of this 
Table A1. Sowing and harvest dates at the ICOS and TERENO cropland study sites.

\begin{tabular}{|c|c|c|c|c|c|}
\hline Site code & Site & Years & Crop & $\begin{array}{r}\text { Sowing } \\
\text { [DD.MM.YYY] }\end{array}$ & $\begin{array}{r}\text { Harvest or plowing } \\
\text { [DD.MM.YYY] }\end{array}$ \\
\hline \multirow[t]{5}{*}{ DE-RuS } & Selhausen & 2015-2016 & Winter barley & 29.09 .2015 & 10.07 .2016 \\
\hline & & 2016 & Greening mix cover crop & 22.08 .2016 & 06.01 .2017 \\
\hline & & 2017 & Sugar beet & 31.03 .2017 & 05.10 .2017 \\
\hline & & 2017-2018 & Winter wheat & 25.10 .2017 & 16.07.2018 \\
\hline & & 2019 & Potato & 26.04.2019 & 03.10 .2019 \\
\hline \multirow[t]{3}{*}{ DE-RuM } & Merzenhausen & 2016 & Potato & 12.04 .2016 & 24.08 .2016 \\
\hline & & 2016-2017 & Winter wheat & 17.10.2016 & 22.07.2017 \\
\hline & & 2017-2018 & Rapeseed & 30.08 .2017 & 16.07.2018 \\
\hline \multirow[t]{18}{*}{ DE-Kli } & Klingenberg & 2003-2004 & Winter barley & 06.09 .2003 & 31.07 .2004 \\
\hline & & 2004-2005 & Rapeseed & 18.08.2004 & 02.08 .2005 \\
\hline & & 2005-2006 & Winter wheat & 25.09 .2005 & 06.09.2006 \\
\hline & & 2007 & Corn & 23.04 .2007 & 02.10 .2007 \\
\hline & & 2008-2009 & Winter barley & 25.04 .2008 & 27.08.2008 \\
\hline & & & & 12.09.2008 & 22.07.2009 \\
\hline & & 2009-2010 & Rapeseed & 25.08.2009 & 24.08 .2010 \\
\hline & & 2010-2011 & Winter wheat & 02.10 .2010 & 22.08.2011 \\
\hline & & 2012 & Corn & 25.04 .2012 & 18.09.2012 \\
\hline & & 2013-2014 & Winter barley & 17.04 .2013 & 24.08 .2013 \\
\hline & & & & 01.10 .2013 & 20.07.2014 \\
\hline & & 2014-2015 & Rapeseed & 21.08 .2014 & 08.08 .2015 \\
\hline & & 2015-2016 & Winter wheat & 18.09.2015 & 24.08.2016 \\
\hline & & 2016-2017 & Radish and brassica cover crop & 01.09 .2016 & 15.03.2017 \\
\hline & & 2017-2018 & Winter barley & 02.04 .2017 & 25.08.2017 \\
\hline & & 2016-2017 & Radish and brassica cover crop & 13.09.2017 & 13.04 .2018 \\
\hline & & 2018 & Corn & 02.05 .2018 & 04.09.2018 \\
\hline & & 2019 & Bean & 23.03.2019 & 18.08.2019 \\
\hline \multirow[t]{17}{*}{ BE-Lon } & Lonzée & 2006-2007 & Winter wheat & 13.10 .2006 & 05.08 .2007 \\
\hline & & 2008 & Sugar beet & 22.04 .2008 & 04.11 .2008 \\
\hline & & 2008-2009 & Winter wheat & 13.11.2008 & 07.08 .2009 \\
\hline & & 2009 & Mustard & 01.09 .2009 & 01.12 .2009 \\
\hline & & 2010 & Potato & 25.04 .2010 & 05.09.2010 \\
\hline & & 2010-2011 & Winter wheat & 14.10 .2010 & 16.08 .2011 \\
\hline & & 2012 & Corn & 14.05 .2012 & 13.10 .2012 \\
\hline & & 2012-2013 & Winter wheat & 25.10 .2012 & 12.08 .2013 \\
\hline & & 2013 & Mustard & 05.09 .2013 & 15.11 .2013 \\
\hline & & 2014 & Potato & 07.04 .2014 & 22.08 .2014 \\
\hline & & 2014-2015 & Winter wheat & 15.10 .2014 & 02.08 .2015 \\
\hline & & 2015 & Mustard & 26.08 .2015 & 09.12 .2015 \\
\hline & & 2016 & Sugar beet & 12.04 .2016 & 27.10 .2016 \\
\hline & & 2016-2017 & Winter wheat & 29.10 .2016 & 30.07 .2017 \\
\hline & & 2017 & Mustard & 07.09.2017 & 08.12 .2017 \\
\hline & & 2018 & Potato & 23.04 .2018 & 11.09.2018 \\
\hline & & 2018-2019 & Winter wheat & 10.10 .2018 & 01.08.2019 \\
\hline
\end{tabular}

phase. Even so, an extended period of freezing temperatures can potentially induce damage to the plant (Lu et al., 2017). This accumulated frost damage is simulated based on the accumulated WDD and average survival probability. When the accumulated WDD reaches a value higher than $1^{\circ} \mathrm{d}$, the leaf carbon from the previous time step $\left(\operatorname{leafc}_{t-1}\right)$, scaled by the average $f_{\text {surv }}$, is moved to the soil carbon litter pool:

leafc $_{t}=$ leafc $_{t-1}\left(1-\right.$ average $\left.f_{\text {surv }}\right)$

for $v f \geq 0.9$ and WDD $>1$.

Once this has occurred, the accumulated WDD is reset to 0 and the tracking of the average $f_{\text {surv }}$ is restated. Corresponding to the leaf carbon reduction, the leaf nitrogen is reduced 
Table A2. Default (control) and new crop-specific (new) phenology and CN allocation parameters for the CFTs sugar beet, potatoes (control parameters are those for the CFT spring wheat), and winter wheat.

\begin{tabular}{|c|c|c|c|c|c|c|c|}
\hline \multirow{2}{*}{$\begin{array}{l}\text { CFT } \\
\text { Parameter set }\end{array}$} & & \multicolumn{2}{|c|}{ Sugar beet } & \multicolumn{2}{|c|}{ Potatoes } & \multicolumn{2}{|c|}{ Winter wheat } \\
\hline & & Control & New & Control & New & Control & New \\
\hline Variable & Units & \multicolumn{6}{|c|}{ Phenology } \\
\hline min_NH_planting_date & MM.DD & 401 & 401 & 401 & 401 & 901 & 901 \\
\hline max_NH_planting_date & MM.DD & 615 & 530 & 615 & 530 & 1130 & 1130 \\
\hline planting_temp & $\mathrm{K}$ & 280.15 & 280.15 & 280.15 & 277.15 & 1000 & 1000 \\
\hline min_planting_temp & $\mathrm{K}$ & 272.15 & 272.15 & 272.15 & 272.15 & 283.15 & 283.15 \\
\hline gddmin & ${ }^{\circ} \mathrm{d}$ & 50 & 60 & 50 & 60 & 50 & 100 \\
\hline mxmat & days & 150 & 180 & 150 & 180 & 330 & 400 \\
\hline baset & ${ }^{\circ} \mathrm{d}$ & 0 & 0 & 0 & 0 & 0 & 0 \\
\hline mxtmp & ${ }^{\circ} \mathrm{C}$ & 26 & 30 & 26 & 30 & 26 & 26 \\
\hline hybgdd & - & 1700 & 2000 & 1700 & 2000 & 1700 & 2000 \\
\hline lfemerg & $\%$ & 0.05 & 0.05 & 0.05 & 0.05 & 0.03 & 0.03 \\
\hline grnfill & $\%$ & 0.6 & 0.65 & 0.6 & 0.65 & 0.4 & 0.6 \\
\hline ztopmx & $\mathrm{m}$ & 1.2 & 0.5 & 1.2 & 0.5 & 1.2 & 1.2 \\
\hline laimx & $\mathrm{m}^{2} \mathrm{~m}^{-2}$ & 7 & 6 & 7 & 6 & 7 & 7 \\
\hline slatop & $\mathrm{m}^{2} \mathrm{gC}^{-1}$ & 0.035 & 0.02 & 0.035 & 0.02 & 0.035 & 0.028 \\
\hline Variable & Units & \multicolumn{6}{|c|}{$\mathrm{CN}$ ratios and allocation } \\
\hline leafcn & $\mathrm{gC} \mathrm{gN}^{-1}$ & 20 & 11 & 20 & 11 & 20 & 20 \\
\hline leafcn_min & ${\mathrm{gC} \mathrm{gN}^{-1}}^{-1}$ & 15 & 8 & 15 & 8 & 15 & 15 \\
\hline leafcn_max & $\mathrm{gC} \mathrm{gN}^{-1}$ & 35 & 20 & 35 & 20 & 35 & 35 \\
\hline frootcn & $\mathrm{gC} \mathrm{gN}^{-1}$ & 42 & 42 & 42 & 42 & 42 & 43 \\
\hline graincn & $\mathrm{gC} \mathrm{gN}^{-1}$ & 50 & 50 & 50 & 50 & 50 & 15 \\
\hline flnr & fraction per $\mathrm{gNm}^{-2}$ & 0.41 & 0.15 & 0.41 & 0.15 & 0.41 & 0.3 \\
\hline
\end{tabular}

Table A3. Textural fractions (sand, silt, and clay percentages) for the ICOS and TERENO cropland study sites averaged for the upper soil layers (up to $50 \mathrm{~cm}$ ) with corresponding reference.

\begin{tabular}{lrrrl}
\hline Site/ID & Sand (\%) & Silt (\%) & Clay (\%) & Ref. \\
\hline Selhausen (DE-RuS) & 16.4 & 63.4 & 14.9 & Brogi et al. (2019) \\
Merzenhausen (DE-RuM) & $16.4^{*}$ & $63.4^{*}$ & $14.9^{*}$ & - \\
Klingenberg (DE-Kli) & 21.5 & 22.8 & 55.7 & Thomas Grünwald (personal communication, 2020) \\
Lonzée (BE-Lon) & $5-10$ & $68-77$ & $18-22$ & Moureaux et al. (2006) \\
\hline
\end{tabular}

* Adopted from the DE-RuS site

from the leaf nitrogen pool to the soil nitrogen litter pool scaled with the parameterized leaf $\mathrm{C} / \mathrm{N}$ ratio for winter wheat of 20 . 
Code availability. The modified model version CLM_ WW_CC is freely available via Zenodo, https://doi.org/10.5281/zenodo.3978092 (Boas, 2020).

Data availability. For the TERENO sites Selhausen (TERENO ID: SE_EC_001 and SE_BK_001) and Merzenhausen (TERENO ID: ME_EC_001, ME_BCK_001), all EC and meteorological data are freely available via the TERENO data portal (TERENO, 2020). EC data for the ICOS study sites at Lonzée (ICOS ID: BE-Lon) and Selhausen (ICOS ID: DE-RuS) are available via the ICOS data portal (ICOS, 2020). Additional data on vegetation and management practices (e.g., LAI, normalized difference vegetation index, canopy heights) were kindly provided by the respective site operators.

Supplement. The supplement related to this article is available online at: https://doi.org/10.5194/gmd-14-573-2021-supplement.

Competing interests. The authors declare that they have no conflict of interest.

Author contributions. TB developed the modified model code; designed, performed, and analyzed the simulation experiments; and prepared the manuscript with contributions from all co-authors. HB, HJHF, DR, AW, and HV supervised the research, co-designed the experiments, and contributed to the manuscript. $\mathrm{MS}, \mathrm{BG}$, and $\mathrm{BH}$ performed pre-processing (e.g., quality control, gap-filling) of the respective site data.

Acknowledgements. The authors gratefully acknowledge Yaqiong $\mathrm{Lu}$ for providing the source code to the winter cereal implementation to CLM4.5 (Lu et al., 2017). Furthermore, the authors gratefully acknowledge the computing time granted on the supercomputer JURECA by the Jülich Supercomputing Centre (JSC). This study is part of the Jülich-University of Melbourne Postgraduate Academy (JUMPA), an international research collaboration between the University of Melbourne, Australia, and the Research Centre Jülich, Germany. This work used data acquired and shared by the TERENO project of the Helmholtz Association, the EU ICOS project of the European Research Infrastructure programme (ESFRI), and the Deutsche Forschungsgemeinschaft (DFG, German Research Foundation) under Germany's Excellence Strategy (EXC 2070-390732324, project PhenoRob).

Financial support. The article processing charges for this openaccess publication were covered by a Research Centre of the Helmholtz Association.

Review statement. This paper was edited by David Lawrence and reviewed by two anonymous referees.

\section{References}

Aaheim, A., Amundsen, H., Dokken, T., and Wei, T.: Impacts and adaptation to climate change in European economies, Glob. Environ. Change, 22, 959-968, https://doi.org/10.1016/j.gloenvcha.2012.06.005, 2012.

Aase, J. K. and Siddoway, F. H.: Crown-Depth Soil Temperatures and Winter Protection for Winter Wheat Survival, Soil Sci. Soc. Am. J., 43, 1229-1233, https://doi.org/10.2136/sssaj1979.03615995004300060036x, 1979.

Barlow, K. M., Christy, B. P., O’Leary, G. J., Riffkin, P. A., and Nuttall, J. G.: Simulating the impact of extreme heat and frost events on wheat crop production: A review, Field Crops Res., 171, 109-119, https://doi.org/10.1016/j.fcr.2014.11.010, 2015.

Basche, A. D., Miguez, F. E., Kaspar, T. C., and Castellano, M. J.: Do cover crops increase or decrease nitrous oxide emissions? A meta-analysis, J. Soil Water Conserv., 69, 471-482, https://doi.org/10.2489/jswc.69.6.471, 2014.

Basche, A. D., Archontoulis, S. V., Kaspar, T. C., Jaynes, D. B., Parkin, T. B., and Miguez, F. E.: Simulating longterm impacts of cover crops and climate change on crop production and environmental outcomes in the Midwestern United States, Agric. Ecosyst. Environ., 218, 95-106, https://doi.org/10.1016/j.agee.2015.11.011, 2016.

Bassu, S., Brisson, N., Durand, J. L., Boote, K., Lizaso, J., Jones, J. W., Rosenzweig, C., Ruane, A. C., Adam, M., Baron, C., Basso, B., Biernath, C., Boogaard, H., Conijn, S., Corbeels, M., Deryng, D., Sanctis, G. D., Gayler, S., Grassini, P., Hatfield, J., Hoek, S., Izaurralde, C., Jongschaap, R., Kemanian, A. R., Kersebaum, K. C., Kim, S. H., Kumar, N. S., Makowski, D., Müller, C., Nendel, C., Priesack, E., Pravia, M. V., Sau, F., Shcherbak, I., Tao, F., Teixeira, E., Timlin, D., and Waha, K.: How do various maize crop models vary in their responses to climate change factors?, Glob. Change Biol., 20, 2301-2320, https://doi.org/10.1111/gcb.12520, 2014.

Bergjord, A. K., Bonesmo, H,. and Skjelvåg, A. O.: Modelling the course of frost tolerance in winter wheat: I. Model development, Eur. J. Agron., 28, 321-330, https://doi.org/10.1016/j.eja.2007.10.002, 2008.

Bergkamp, B., Impa, S. M., Asebedo, A. R., Fritz, A. K., and Jagadish, S. V. K.: Prominent winter wheat varieties response to post-flowering heat stress under controlled chambers and field based heat tents, Field Crops Res., 222, 143-152, https://doi.org/10.1016/j.fcr.2018.03.009, 2018.

Betts, R.: Integrated approaches to climate-crop modelling: needs and challenges, Philos. T. Roy. Soc. B, 360, 2049-2065, https://doi.org/10.1098/rstb.2005.1739, 2005.

Biradar, C. M. and Xiao, X.: Quantifying the area and spatial distribution of double- and triple-cropping croplands in India with multi-temporal MODIS imagery in 2005, Int. J. Remote Sens., 32, 367-386, https://doi.org/10.1080/01431160903464179, 2011.

Boas, T.: Modified model version CLM_WW_CC, Zenodo, https://doi.org/10.5281/zenodo.3978092, 2020.

Bogena, H. R., Montzka, C., Huisman, J. A., Graf, A., Schmidt, M., Stockinger, M., von Hebel, C., Hendricks-Franssen, H. J., van der Kruk, J., Tappe, W., Lücke, A., Baatz, R., Bol, R., Groh, J., Pütz, T., Jakobi, J., Kunkel, R., Sorg, J., and Vereecken, H.: The TERENO-Rur Hydrological Observatory: A 
Multiscale Multi-Compartment Research Platform for the Advancement of Hydrological Science, Vadose Zone J., 17, 4-9, https://doi.org/10.2136/vzj2018.03.0055, 2018.

Brogi, C., Huisman, J. A., Pätzold, S., von Hebel, C., Weihermüller, L., Kaufmann, M. S., van der Kruk, J., and Vereecken, H.: Large-scale soil mapping using multi-configuration EMI and supervised image classification, Geoderma, 335, 133-148, https://doi.org/10.1016/j.geoderma.2018.08.001, 2019.

Buysse, P., Bodson, B., De Debacq, A., Ligne, A., Heinesch, B., Manise, T., Moureaux, C., and Aubinet, M.: Carbon budget measurement over 12 years at a crop production site in the silty-loam region in Belgium, Agr. Forest Meteorol., 246, 241-255, 2017.

Carrer, D., Pique, G., Ferlicoq, M., Ceamanos, X., and Ceschia, E.: What is the potential of cropland albedo management in the fight against global warming? A case study based on the use of cover crops, Environ. Res. Lett., 13, 044030, https://doi.org/10.1088/1748-9326/aab650, 2018.

Chen, M., Griffis, T. J., Baker, J., Wood, J. D., and Xiao, K.: Simulating crop phenology in the Community Land Model and its impact on energy and carbon fluxes: Evaluation of CLM crop simulations, J. Geophys. Res.-Biogeo., 120, 310-325, https://doi.org/10.1002/2014JG002780, 2015.

Ceglar, A., van der Wijngaart, R., de Wit, A., Lecerf, R., Boogaard, H., Seguini, L., van den Berg, M., Toreti, A., Zampieri, M., Fumagalli, D., and Baruth, B.: Improving WOFOST model to simulate winter wheat phenology in Europe: Evaluation and effects on yield, Agric. Syst., 168, 168-180, https://doi.org/10.1016/j.agsy.2018.05.002, 2019.

Chakraborty, S. and Newton, A. C.: Climate change, plant diseases and food security: an overview, Plant Pathol., 60, 2-14, https://doi.org/10.1111/j.1365-3059.2010.02411.x, 2011.

Challinor, A. J., Watson, J., Lobell, D. B., Howden, S. M., Smith, D. R., and Chhetri, N.: A meta-analysis of crop yield under climate change and adaptation, Nat. Clim. Change, 4, 287-291, https://doi.org/10.1038/nclimate2153, 2014.

Chen, M., Griffis, T. J., Baker, J. M., Wood, J. D., Meyers, T., and Suyker, A.: Comparing crop growth and carbon budgets simulated across AmeriFlux agricultural sites using the Community Land Model (CLM), Agr. Forest Meteorol., 256-257, 315-333, https://doi.org/10.1016/j.agrformet.2018.03.012, 2018.

Cheng, Y., Huang, M., Chen, M., Guan, K., Bernacchi, C., Peng, B., and Tan, Z.: Parameterizing Perennial Bioenergy Crops in Version 5 of the Community Land Model Based on Site-Level Observations in the Central Midwestern United States, J. Adv. Model. Earth Syst., 12, e2019MS001719, https://doi.org/10.1029/2019MS001719, 2020.

Chouard, P.: Vernalization and its Relations to Dormancy, Annu. Rev. Plant Physio., 11, 191-238, https://doi.org/10.1146/annurev.pp.11.060160.001203, 1960.

Deryng, D., Conway, D., Ramankutty, N., Price, J., and Warren, R.: Global crop yield response to extreme heat stress under multiple climate change futures, Environ. Res. Lett., 9, 034011, https://doi.org/10.1088/1748-9326/9/3/034011, 2014.

Eder, F., Schmidt, M., Damian, T., Träumner, K., and Mauder, M.: Mesoscale Eddies Affect Near-Surface Turbulent Exchange: Evidence from Lidar and Tower Measurements, J. Appl. Meteorol. Climatol., 54, 189-206, https://doi.org/10.1175/JAMC-D14-0140.1, 2015.
Elliott, J., Müller, C., Deryng, D., Chryssanthacopoulos, J., Boote, K. J., Büchner, M., Foster, I., Glotter, M., Heinke, J., Iizumi, T., Izaurralde, R. C., Mueller, N. D., Ray, D. K., Rosenzweig, C., Ruane, A. C., and Sheffield, J.: The Global Gridded Crop Model Intercomparison: data and modeling protocols for Phase 1 (v1.0), Geosci. Model Dev., 8, 261-277, https://doi.org/10.5194/gmd-8261-2015, 2015.

Eurostat: Agriculture, forestry and fishery statistics, 2018 edition, European Union, https://doi.org/10.2785/340432, 2018.

Fang, H., Liang, S., Hoogenboom, G., Teasdale, J., and Cavigelli, M.: Corn-yield estimation through assimilation of remotely sensed data into the CSM-CERESMaize model, Int. J. Remote Sens., 29, 3011-3032, https://doi.org/10.1080/01431160701408386, 2008.

Fisher, R. A., Wieder, W. R., Sanderson, B. M., Koven, C. D., Oleson, K. W., Xu, C., Fisher, J. B., Shi, M., Walker, A. P., and Lawrence, D. M.: Parametric Controls on Vegetation Responses to Biogeochemical Forcing in the CLM5, J. Adv. Model. Earth Sy., 11, 2879-2895, https://doi.org/10.1029/2019MS001609, 2019.

Fowler, D. B., Limin, A. E., and Ritchie, J. T.: Low-Temperature Tolerance in Cereals: Model and Genetic Interpretation, Crop Sci., 39, 626-633, https://doi.org/10.2135/cropsci1999.0011183X003900020002x, 1999.

Gan, Y. T., Liang, B. C., Liu, L. P., Wang, X. Y., and McDonald, C. L.: C:N ratios and carbon distribution profile across rooting zones in oilseed and pulse crops, Crop Pasture Sci., 62, 496, https://doi.org/10.1071/CP10360, 2011.

Gosling, S. N.: The likelihood and potential impact of future change in the large-scale climate-earth system on ecosystem services, Environ. Sci. Policy, 27, S15-S31, https://doi.org/10.1016/j.envsci.2012.03.011, 2013.

Graf, A.: Gap-filling meteorological variables with Empirical Orthogonal Functions, EGU General Assembly, Vienna, Austria, 23-28 April 2017, EGU2017-8491, 2017.

Graf, A., Klosterhalfen, A., Arriga, N., Bernhofer, C., Bogena, H., Bornet, F., Brüggemann, N., Brümmer, C., Buchmann, N., Chi, J., Chipeaux, C., Cremonese, E., Cuntz, M., Dušek, J., ElMadany, T. S., Fares, S., Fischer, M., Foltýnová, L., Gharun, M., Ghiasi, S., Gielen, B., Gottschalk, P., Grünwald, T., Heinemann, G., Heinesch, B., Heliasz, M., Holst, J., Hörtnagl, L., Ibrom, A., Ingwersen, J., Jurasinski, G., Klatt, J., Knohl, A., Koebsch, F., Konopka, J., Korkiakoski, M., Kowalska, N., Kremer, P., Kruijt, B., Lafont, S., Léonard, J., De Ligne, A., Longdoz, B., Loustau, D., Magliulo, V., Mammarella, I., Manca, G., Mauder, M., Migliavacca, M., Mölder, M., Neirynck, J., Ney, P., Nilsson, M., Paul-Limoges, E., Peichl, M., Pitacco, A., Poyda, A., Rebmann, C., Roland, M., Sachs, T., Schmidt, M., Schrader, F., Siebicke, L., Šigut, L., Tuittila, E.-S., Varlagin, A., Vendrame, N., Vincke, C., Völksch, I., Weber, S., Wille, C., Wizemann, H.-D., Zeeman, M. and Vereecken, H.: Altered energy partitioning across terrestrial ecosystems in the European drought year 2018, Philos. T. R. Soc. B Biol. Sci., 375, 20190524, https://doi.org/10.1098/rstb.2019.0524, 2020.

Groff, S.: The past, present, and future of the cover crop industry, J. Soil Water Conserv., 70, 130A-133A, https://doi.org/10.2489/jswc.70.6.130A, 2015. 
Guérif, M. and Duke, C. L.: Adjustment procedures of a crop model to the site specific characteristics of soil and crop using remote sensing data assimilation, Agric. Ecosyst. Environ., 81, 57-69, https://doi.org/10.1016/S0167-8809(00)00168-7, 2000.

Han, X., Franssen, H.-J. H., Montzka, C., and Vereecken, H.: Soil moisture and soil properties estimation in the Community Land Model with synthetic brightness temperature observations, Water Resour. Res., 50, 6081-6105, https://doi.org/10.1002/2013WR014586, 2014.

Huang, J., Tian, L., Liang, S., Ma, H., Becker-Reshef, I., Huang, Y., Su, W., Zhang, X., Zhu, D., and Wu, W.: Improving winter wheat yield estimation by assimilation of the leaf area index from Landsat TM and MODIS data into the WOFOST model, Agr. Forest Meteorol., 204, 106-121, https://doi.org/10.1016/j.agrformet.2015.02.001, 2015.

Hunter, M. C., White, C. M., Kaye, J. P., and Kemanian, A. R.: Ground-Truthing a Recent Report of Cover CropInduced Winter Warming, Agric. Environ. Lett., 4, 190007, https://doi.org/10.2134/ael2019.03.0007, 2019.

ICOS: Integrated Carbon Observation System Carbon Portal, available at: https://www.icos-cp.eu/, last access: 15 May 2020.

Jin, X., Kumar, L., Li, Z., Feng, H., Xu, X., Yang, G., and Wang, J.: A review of data assimilation of remote sensing and crop models, Eur. J. Agron., 92, 141-152, https://doi.org/10.1016/j.eja.2017.11.002, 2018.

Kattge, J., Díaz, S., Lavorel, S., Prentice, I. C., Leadley, P., Bönisch, G., Garnier, E., Westoby, M., Reich, P. B., Wright, I. J., Cornelissen, J. H. C., Violle, C., Harrison, S. P., Bodegom, P. M. V., Reichstein, M., Enquist, B.J., Soudzilovskaia, N. A., Ackerly, D. D., Anand, M., Atkin, O., Bahn, M., Baker, T. R., Baldocchi, D., Bekker, R., Blanco, C. C., Blonder, B., Bond, W.J., Bradstock, R., Bunker, D.E., Casanoves, F., Cavender-Bares, J., Chambers, J. Q., Iii, F. S. C., Chave, J., Coomes, D., Cornwell, W. K., Craine, J.M., Dobrin, B. H., Duarte, L., Durka, W., Elser, J., Esser, G., Estiarte, M., Fagan, W. F., Fang, J., Fernández-Méndez, F., Fidelis, A., Finegan, B., Flores, O., Ford, H., Frank, D., Freschet, G. T., Fyllas, N. M., Gallagher, R. V., Green, W. A., Gutierrez, A. G., Hickler, T., Higgins, S. I., Hodgson, J. G., Jalili, A., Jansen, S., Joly, C. A., Kerkhoff, A. J., Kirkup, D., Kitajima, K., Kleyer, M., Klotz, S., Knops, J. M. H., Kramer, K., Kühn, I., Kurokawa, H., Laughlin, D., Lee, T. D., Leishman, M., Lens, F., Lenz, T., Lewis, S. L., Lloyd, J., Llusià, J., Louault, F., Ma, S., Mahecha, M. D., Manning, P., Massad, T., Medlyn, B. E., Messier, J., Moles, A. T., Müller, S. C., Nadrowski, K., Naeem, S., Niinemets, Ü., Nöllert, S., Nüske, A., Ogaya, R., Oleksyn, J., Onipchenko, V.G., Onoda, Y., Ordoñez, J., Overbeck, G., Ozinga, W. A., Patiño, S., Paula, S., Pausas, J.G., Peñuelas, J., Phillips, O. L., Pillar, V., Poorter, H., Poorter, L., Poschlod, P., Prinzing, A., Proulx, R., Rammig, A., Reinsch, S., Reu, B., Sack, L., Salgado-Negret, B., Sardans, J., Shiodera, S., Shipley, B., Siefert, A., Sosinski, E., Soussana, J.F., Swaine, E., Swenson, N., Thompson, K., Thornton, P., Waldram, M., Weiher, E., White, M., White, S., Wright, S. J., Yguel, B., Zaehle, S., Zanne, A. E., and Wirth, C.: TRY - a global database of plant traits, Glob. Change Biol., 17, 2905-2935, https://doi.org/10.1111/j.1365-2486.2011.02451.x, 2011.

Kaye, J. P. and Quemada, M.: Using cover crops to mitigate and adapt to climate change. A review, Agron. Sustain. Dev., 37, 4, https://doi.org/10.1007/s13593-016-0410-x, 2017.
Kennedy, D., Swenson, S. C., Oleson, K. W., Lawrence, D. M., Fisher, R., and Gentine, P.: Representing Plant Hydraulics in a Global Model: Updates to the Community Land Model, AGU Fall Meeting 2017, New Orleans, USA, 11-15 December 2017, abstract: B12D-05, 2017.

Kennedy, D., Swenson, S., Oleson, K. W., Lawrence, D. M., Fisher, R., da Costa, A. C. L., and Gentine, P.: Implementing Plant Hydraulics in the Community Land Model, Version 5, J. Adv. Model. Earth Sy., 11, 485-513, https://doi.org/10.1029/2018MS001500, 2019.

Kollas, C., Kersebaum, K. C., Nendel, C., Manevski, K., Müller, C., Palosuo, T., Armas-Herrera, C. M., Beaudoin, N., Bindi, M., Charfeddine, M., Conradt, T., Constantin, J., Eitzinger, J., Ewert, F., Ferrise, R., Gaiser, T., de Cortazar-Atauri, I. G., Giglio, L., Hlavinka, P., Hoffmann, H., Hoffmann, M. P., Launay, M., Manderscheid, R., Mary, B., Mirschel, W., Moriondo, M., Olesen, J. E., Öztürk, I., Pacholski, A., Ripoche-Wachter, D., Roggero, P. P., Roncossek, S., Rötter, R. P., Ruget, F., Sharif, B., Trnka, M., Ventrella, D., Waha, K., Wegehenkel, M., Weigel, H.-J., and Wu, L.: Crop rotation modelling-A European model intercomparison, Eur. J. Agron., 70, 98-111, https://doi.org/10.1016/j.eja.2015.06.007, 2015.

Kucharik, C. J. and Brye, K. R.: Integrated BIosphere Simulator (IBIS) Yield and Nitrate Loss Predictions for Wisconsin Maize Receiving Varied Amounts of Nitrogen Fertilizer, J. Environ. Qual., 32, 247-268, https://doi.org/10.2134/jeq2003.2470, 2003.

Kutsch, W. L., Aubinet, M., Buchmann, N., Smith, P., Osborne, B., Eugster, W., Wattenbach, M., Schrumpf, M., Schulze, E. D., Tomelleri, E., Ceschia, E., Bernhofer, C., Béziat, P., Carrara, A., Di Tommasi, P., Grünwald, T., Jones, M., Magliulo, V., Marloie, O., Moureaux, C., Olioso, A., Sanz, M. J., Saunders, M., Søgaard, H., and Ziegler, W.: The net biome production of full crop rotations in Europe, Agric. Ecosyst. Environ., 139, 336345, https://doi.org/10.1016/j.agee.2010.07.016, 2010.

Launay, M. and Guerif, M.: Assimilating remote sensing data into a crop model to improve predictive performance for spatial applications, Agric. Ecosyst. Environ., 111, 321-339, https://doi.org/10.1016/j.agee.2005.06.005, 2005.

Lawrence, D. M., Oleson, K. W., Flanner, M. G., Thornton, P. E., Swenson, S. C., Lawrence, P. J., Zeng, X., Yang, Z.-L., Levis, S., Sakaguchi, K., Bonan, G. B., and Slater, A. G.: Parameterization improvements and functional and structural advances in Version 4 of the Community Land Model, J. Adv. Model. Earth Syst., 3, 1, https://doi.org/10.1029/2011MS00045, 2011.

Lawrence, D. M., Fisher, R., Koven, C., Oleson, K., Svenson, S., Vertenstein, M. (coordinating lead authors), Andre, B., Bonan, G., Ghimire, B., van Kampenhout, L., Kennedy, D., Kluzek, E., Knox, R., Lawrence, P., Li, F., Li, H., Lombardozzi, D., Lu, Y., Perket, J., Riley, W., Sacks, W., Shi, M., Wieder, W., Xu, C. (lead authors), Ali, A., Badger, A., Bisht, G., Broxton, P., Brunke, M., Buzan, J., Clark, M., Craig, T., Dahlin, K., Drewniak, B., Emmons, L., Fisher, J., Flanner, M., Gentine, P., Lenaerts, J., Levis, S., Leung, L. R., Lipscomb, W., Pelletier, J., Ricciuto, D. M., Sanderson, B., Shuman, J., Slater, A., Subin, Z., Tang, J., Tawfik, A., Thomas, Q., Tilmes, S., Vitt, F., and Zeng, X.: Technical Description of version 5.0 of the Community Land Model (CLM), Natl. Cent. Atmospheric Res. (NCAR), available at: http://www. cesm.ucar.edu/models/cesm2/land/CLM50_Tech_Note.pdf (last access: 15 June 2020), 2018. 
Lawrence, P., Lawrence, D. M., Hurtt, G. C., and Calvin, K. V.: Advancing our understanding of the impacts of historic and projected land use in the Earth System: The Land Use Model Intercomparison Project (LUMIP), AGU Fall Meeting 2019, San Francisco, USA, 9-13 December 2019, abstract: GC23B-01, 2019

Leng, G., Huang, M., Tang, Q., Sacks, W. J., Lei, H., and Leung, L. R.: Modeling the effects of irrigation on land surface fluxes and states over the conterminous United States: Sensitivity to input data and model parameters, J. Geophys. Res.-Atmos., 118, 97899803, https://doi.org/10.1002/jgrd.50792, 2013.

Levis, S., Bonan, G. B., Kluzek, E., Thornton, P. E., Jones, A., Sacks, W. J., and Kucharik, C. J.: Interactive Crop Management in the Community Earth System Model (CESM1): Seasonal Influences on Land-Atmosphere Fluxes, J. Climate, 25, 48394859, https://doi.org/10.1175/JCLI-D-11-00446.1, 2012.

Levis, S., Badger, A., Drewniak, B., Nevison, C., and Ren, X.: CLMcrop yields and water requirements: avoided impacts by choosing RCP 4.5 over 8.5, Climatic Change, 146, 501-515, https://doi.org/10.1007/s10584-016-1654-9, 2018.

Li, L., Friedl, M. A., Xin, Q., Gray, J., Pan, Y., and Frolking, S.: Mapping Crop Cycles in China Using MODIS-EVI Time Series, Remote Sens., 6, 2473-2493, https://doi.org/10.3390/rs6032473, 2014.

Lobell, D. B., Bala, G., and Duffy, P. B.: Biogeophysical impacts of cropland management changes on climate, Geophys. Res. Lett., 33, L06708, https://doi.org/10.1029/2005GL025492, 2006.

Lobell, D. B., Schlenker, W., and Costa-Roberts, J.: Climate Trends and Global Crop Production Since 1980, Science, 333, 616-620, https://doi.org/10.1126/science.1204531, 2011.

Lokupitiya, E., Denning, S., Paustian, K., Baker, I., Schaefer, K., Verma, S., Meyers, T., Bernacchi, C. J., Suyker, A., and Fischer, M.: Incorporation of crop phenology in Simple Biosphere Model (SiBcrop) to improve land-atmosphere carbon exchanges from croplands, Biogeosciences, 6, 969-986, https://doi.org/10.5194/bg-6-969-2009, 2009.

Lombardozzi, D. L., Bonan, G. B., Wieder, W., Grandy, A. S., Morris, C., and Lawrence, D. L.: Cover Crops May Cause Winter Warming in Snow-Covered Regions, Geophys. Res. Lett., 45, 9889-9897, https://doi.org/10.1029/2018GL079000, 2018.

Lombardozzi, D. L., Lu, Y., Lawrence, P. J., Lawrence, D. M., Swenson, S., Oleson, K. W., Wieder, W. R., and Ainsworth, E. A.: Simulating Agriculture in the Community Land Model Version 5, J. Geophys. Res.-Biogeo., 125, e2019JG005529, https://doi.org/10.1029/2019JG005529, 2020.

Lu, Y., Williams, I. N., Bagley, J. E., Torn, M. S., and Kueppers, L. M.: Representing winter wheat in the Community Land Model (version 4.5), Geosci. Model Dev., 10, 1873-1888, https://doi.org/10.5194/gmd-10-1873-2017, 2017.

Ma, S., Churkina, G., and Trusilova, K.: Investigating the impact of climate change on crop phenological events in Europe with a phenology model, Int. J. Biometeorol., 56, 749-763, https://doi.org/10.1007/s00484-011-0478-6, 2012.

McDermid, S. S., Mearns, L. O. and Ruane, A. C.: Representing agriculture in Earth System Models: Approaches and priorities for development, J. Adv. Model. Earth Sy., 9, 2230-2265, https://doi.org/10.1002/2016MS000749, 2017.

Möller, K. and Reents, H.-J.: Effects of various cover crops after peas on nitrate leaching and nitrogen supply to succeeding win- ter wheat or potato crops, J. Plant Nutr. Soil Sci., 172, 277-287, https://doi.org/10.1002/jpln.200700336, 2009.

Moureaux, C.: Annual net ecosystem carbon exchange by a sugar beet crop, Agr. Forest Meteorol., 139, 25-39, https://doi.org/10.1016/j.agrformet.2006.05.009, 2006.

Moureaux, C., Debacq, A., Bodson, B., Heinesch, B., and Aubinet, M.: Annual net ecosystem carbon exchange by a sugar beet crop, Agr. Forest Meteorol., 139, 25-39, https://doi.org/10.1016/j.agrformet.2006.05.009, 2006.

Moureaux, C., Debacq, A., Hoyaux, J., Suleau, M., Tourneur, D., Vancutsem, F., Bodson, B., and Aubinet, M.: Carbon balance assessment of a Belgian winter wheat crop (Triticum aestivum L.), Glob. Change Biol., 14, 1353-1366, https://doi.org/10.1111/j.1365-2486.2008.01560.x, 2008.

Naz, B. S., Kurtz, W., Montzka, C., Sharples, W., Goergen, K., Keune, J., Gao, H., Springer, A., Hendricks Franssen, H.-J., and Kollet, S.: Improving soil moisture and runoff simulations at $3 \mathrm{~km}$ over Europe using land surface data assimilation, Hydrol. Earth Syst. Sci., 23, 277-301, https://doi.org/10.5194/hess-23277-2019, 2019.

Ney, P.: Partitioning of carbon dioxide exchange in rapidly and slowly changing ecosystems, available at: https://bonndoc.ulb. uni-bonn.de/xmlui/handle/20.500.11811/8100 (last access: 24 January 2020), 2019.

Ney, P. and Graf, A.: High-Resolution Vertical Profile Measurements for Carbon Dioxide and Water Vapour Concentrations Within and Above Crop Canopies, Bound.-Lay. Meteorol., 166, 449-473, https://doi.org/10.1007/s10546-017-0316-4, 2018.

Niu, G.-Y., Yang, Z.-L., Mitchell, K. E., Chen, F., Ek, M. B., Barlage, M., Kumar, A., Manning, K., Niyogi, D., Rosero, E., Tewari, M. and Xia, Y.: The community Noah land surface model with multiparameterization options (Noah-MP): 1. Model description and evaluation with localscale measurements, J. Geophys. Res.-Atmos., 116, D12109, https://doi.org/10.1029/2010JD015139, 2011.

Olesen, J. E., Trnka, M., Kersebaum, K. C., Skjelvåg, A. O., Seguin, B., Peltonen-Sainio, P., Rossi, F., Kozyra, J., and Micale, F.: Impacts and adaptation of European crop production systems to climate change, Eur. J. Agron., 34, 96-112, https://doi.org/10.1016/j.eja.2010.11.003, 2011.

Oleson, K. W., Lawrence, D. M., B, G., Flanner, M. G., Kluzek, E., J, P., Levis, S., Swenson, S. C., Thornton, E., Feddema, J., Heald, C. L., Lamarque, J., Niu, G., Qian, T., Running, S., Sakaguchi, K., Yang, L., Zeng, X., Zeng, X., and Decker, M.: Technical Description of version 4.0 of the Community Land Model (CLM), 266, https://doi.org/10.5065/D6FB50WZ, 2010.

Osborne, T., Gornall, J., Hooker, J., Williams, K., Wiltshire, A., Betts, R., and Wheeler, T.: JULES-crop: a parametrisation of crops in the Joint UK Land Environment Simulator, Geosci. Model Dev., 8, 1139-1155, https://doi.org/10.5194/gmd-8-11392015, 2015.

Ozdogan, M., Rodell, M., Beaudoing, H. K., and Toll, D. L.: Simulating the Effects of Irrigation over the United States in a Land Surface Model Based on SatelliteDerived Agricultural Data, J. Hydrometeorol., 11, 171-184, https://doi.org/10.1175/2009JHM1116.1, 2010.

Palosuo, T., Kersebaum, K. C., Angulo, C., Hlavinka, P., Moriondo, M., Olesen, J. E., Patil, R. H., Ruget, F., Rumbaur, C., Takáč, J., Trnka, M., Bindi, M., Çaldağ, B., Ewert, F., Ferrise, R., Mirschel, 
W., Şaylan, L., Šiška, B., and Rötter, R.: Simulation of winter wheat yield and its variability in different climates of Europe: A comparison of eight crop growth models, Eur. J. Agron., 35, 103-114, https://doi.org/10.1016/j.eja.2011.05.001, 2011.

Peel, M. C., Finlayson, B. L., and McMahon, T. A.: Updated world map of the Köppen-Geiger climate classification, Hydrol. Earth Syst. Sci., 11, 1633-1644, https://doi.org/10.5194/hess-11-16332007, 2007.

Plaza-Bonilla, D., Nolot, J.-M., Raffaillac, D., and Justes, E.: Cover crops mitigate nitrate leaching in cropping systems including grain legumes: Field evidence and model simulations, Agric. Ecosyst. Environ., 212, 1-12, https://doi.org/10.1016/j.agee.2015.06.014, 2015.

Post, H., Vrugt, J. A., Fox, A., Vereecken, H., and HendricksFranssen, H.-J.: Estimation of Community Land Model parameters for an improved assessment of net carbon fluxes at European sites, J. Geophys. Res.-Biogeo., 122, 661-689, https://doi.org/10.1002/2015JG003297, 2017.

Prescher, A.-K., Grünwald, T., and Bernhofer, C.: Land use regulates carbon budgets in eastern Germany: from NEE to NBP, Agr. Forest Meteorol., 150, 1016-1025, https://doi.org/10.1016/j.agrformet.2010.03.008, 2010.

Reichenau, T. G., Korres, W., Schmidt, M., Graf, A., Welp, G., Meyer, N., Stadler, A., Brogi, C., and Schneider, K.: A comprehensive dataset of vegetation states, fluxes of matter and energy, weather, agricultural management, and soil properties from intensively monitored crop sites in western Germany, Earth Syst. Sci. Data, 12, 2333-2364, https://doi.org/10.5194/essd-12-23332020, 2020.

Rosenzweig, C., Elliott, J., Deryng, D., Ruane, A. C., Müller, C., Arneth, A., Boote, K. J., Folberth, C., Glotter, M., Khabarov, N., Neumann, K., Piontek, F., Pugh, T. A. M., Schmid, E., Stehfest, E., Yang, H., and Jones, J. W.: Assessing agricultural risks of climate change in the 21 st century in a global gridded crop model intercomparison, P. Natl. Acad. Sci. USA., 111, 32683273, https://doi.org/10.1073/pnas.1222463110, 2014.

Sainju, U. M., Whitehead, W. F., and Singh, B. P.: Cover crops and nitrogen fertilization effects on soil aggregation and carbon and nitrogen pools, Can. J. Soil Sci., 83, 155-165, https://doi.org/10.4141/S02-056, 2003.

Sánchez-Sastre, L. F., Martín-Ramos, P., Navas-Gracia, L. M., Hernández-Navarro, S., and Martín-Gil, J.: Impact of Climatic Variables on Carbon Content in Sugar Beet Root, Agronomy, 8, 147, https://doi.org/10.3390/agronomy8080147, 2018.

Semenov, M. A. and Shewry, P. R.: Modelling predicts that heat stress, not drought, will increase vulnerability of wheat in Europe, Sci. Rep.-UK, 1, 1-5, https://doi.org/10.1038/srep00066, 2011.

Sharma, S. D., Kumar, P., Bhardwaj, S. K., and Chandel, A.: Agronomic performance, nutrient cycling and microbial biomass in soil as affected by pomegranate based multiple crop sequencing, Sci. Hortic., 197, 504-515, https://doi.org/10.1016/j.scienta.2015.10.013, 2015.

Sheng, M., Liu, J., Zhu, A.-X., Rossiter, D. G., Zhu, L., and Peng, G.: Evaluation of CLM-Crop for maize growth simulation over Northeast China, Ecol. Model., 377, 26-34, https://doi.org/10.1016/j.ecolmodel.2018.03.005, 2018.

Smit, B., Janssens, B., Haagsma, W., Hennen, W., Adrados Jose, L., and Kathage, J.: Adoption of cover crops for climate change mitigation in the EU, EUR - Scientific and Technical Research Reports, Publications Office of the European Union, available at: https://publications.jrc.ec.europa.eu/repository/handle/ 111111111/57996 (last access: 7 May 2020), 2019.

Statista: Yield statistics of winter wheat for Germany from 2006 to 2019, available at: https://de.statista.com/statistik/daten/studie/ 262303/umfrage/erntemenge-von-weizen-in-deutschland/, last access: 1 June 2020.

Stehfest, E., Heistermann, M., Priess, J. A., Ojima, D. S., and Alcamo, J.: Simulation of global crop production with the ecosystem model DayCent, Ecol. Model., 209, 203-219, https://doi.org/10.1016/j.ecolmodel.2007.06.028, 2007.

Streck, N. A., Weiss, A., and Baenziger, P. S.: A Generalized Vernalization Response Function for Winter Wheat, Agron. J., 95, 155-159, https://doi.org/10.2134/agronj2003.1550, 2003.

Sulis, M., Langensiepen, M., Shrestha, P., Schickling, A., Simmer, C., and Kollet, S. J.: Evaluating the Influence of PlantSpecific Physiological Parameterizations on the Partitioning of Land Surface Energy Fluxes, J. Hydrometeorol., 16, 517-533, https://doi.org/10.1175/JHM-D-14-0153.1, 2015.

Tai, A. P. K., Martin, M. V., and Heald, C. L.: Threat to future global food security from climate change and ozone air pollution, Nat. Clim. Change, 4, 817-821, https://doi.org/10.1038/nclimate2317, 2014.

TERENO: TERrestrial ENvironment Observatories data portal, available at: http://www.tereno.net/ddp/, last access: 31 May 2020.

Thaler, S., Eitzinger, J., Trnka, M., and Dubrovsky, M.: Impacts of climate change and alternative adaptation options on winter wheat yield and water productivity in a dry climate in Central Europe, J. Agric. Sci., 150, 537-555, https://doi.org/10.1017/S0021859612000093, 2012.

Thornton, P. E. and Rosenbloom, N. A.: Ecosystem model spinup: Estimating steady state conditions in a coupled terrestrial carbon and nitrogen cycle model, Ecol. Model., 189, 25-48, https://doi.org/10.1016/j.ecolmodel.2005.04.008, 2005.

Tiemann, L. K., Grandy, A. S., Atkinson, E. E., Marin-Spiotta, E., and McDaniel, M. D.: Crop rotational diversity enhances belowground communities and functions in an agroecosystem, Ecol. Lett., 18, 761-771, https://doi.org/10.1111/ele.12453, 2015.

Twine, T. E. and Kucharik, C. J.: Climate impacts on net primary productivity trends in natural and managed ecosystems of the central and eastern United States, Agr. Forest Meteorol., 149, 2143-2161, https://doi.org/10.1016/j.agrformet.2009.05.012, 2009.

Urban, D., Roberts, M. J., Schlenker, W., and Lobell, D. B.: Projected temperature changes indicate significant increase in interannual variability of U.S. maize yields, Climatic Change, 112, 525-533, https://doi.org/10.1007/s10584-012-0428-2, 2012.

Van den Hoof, C., Hanert, E., and Vidale, P. L.: Simulating dynamic crop growth with an adapted land surface model - JULES-SUCROS: Model development and validation, Agr. Forest Meteorol., 151, 137-153, https://doi.org/10.1016/j.agrformet.2010.09.011, 2011.

Vazifedoust, M., Dam, J. C. van, Bastiaanssen, W. G. M., and Feddes, R. A.: Assimilation of satellite data into agrohydrological models to improve crop yield forecasts, Int. J. Remote Sens., 30, 2523-2545, https://doi.org/10.1080/01431160802552769, 2009. 
Verhoef, A. and Egea, G.: Modeling plant transpiration under limited soil water: Comparison of different plant and soil hydraulic parameterizations and preliminary implications for their use in land surface models, Agr. Forest Meteorol., 191, 22-32, https://doi.org/10.1016/j.agrformet.2014.02.009, 2014.

Vermeulen, S. J., Campbell, B. M., and Ingram, J. S. I.: Climate Change and Food Systems, Annu. Rev. Environ. Resour., 37, 195-222, https://doi.org/10.1146/annurev-environ-020411130608, 2012.

Vico, G., Hurry, V. and Weih, M.: Snowed in for survival: Quantifying the risk of winter damage to overwintering field crops in northern temperate latitudes, Agr. Forest Meteorol., 197, 65-75, https://doi.org/10.1016/j.agrformet.2014.06.003, 2014.

Webler, G., Roberti, D. R., Cuadra, S. V., Moreira, V. S., and Costa, M. H.: Evaluation of a Dynamic Agroecosystem Model (AgroIBIS) for Soybean in Southern Brazil, Earth Interact., 16, 1-15, https://doi.org/10.1175/2012EI000452.1, 2012.

White, E. M. and Wilson, F. E. A.: Responses of Grain Yield, Biomass and Harvest Index and Their Rates of Genetic Progress to Nitrogen Availability in Ten Winter Wheat Varieties, Ir. J. Agric. Food Res., 45, 85-101, 2006.
Whitmore, A. P. and Groot, J. J. R.: The decomposition of sugar beet residues: mineralization versus immobilization in contrasting soil types, Plant Soil, 192, 237-247, https://doi.org/10.1023/A:1004288828793, 1997.

de Wit, A. J. W. and van Diepen, C. A.: Crop model data assimilation with the Ensemble Kalman filter for improving regional crop yield forecasts, Agric. For. Meteorol., 146, 38-56, https://doi.org/10.1016/j.agrformet.2007.05.004, 2007.

Wutzler, T., Lucas-Moffat, A., Migliavacca, M., Knauer, J., Sickel, K., Šigut, L., Menzer, O., and Reichstein, M.: Basic and extensible post-processing of eddy covariance flux data with REddyProc, Biogeosciences, 15, 5015-5030, https://doi.org/10.5194/bg-15-5015-2018, 2018.

$\mathrm{Xu}, \mathrm{H} .$, Twine, T. E., and Girvetz, E.: Climate Change and Maize Yield in Iowa, Plos One, 11, e0156083, https://doi.org/10.1371/journal.pone.0156083, 2016.

Zheng, H., Wang, Y., Zhao, J., Shi, X., Ma, Z., and Fan, M.: Tuber formation as influenced by the $\mathrm{C}: \mathrm{N}$ ratio in potato plants, J. Plant Nutr. Soil Sci., 181, 686-693, https://doi.org/10.1002/jpln.201700571, 2018. 